\title{
Glioblastomas with oligodendroglial component - common origin of the different histological parts and genetic subclassification
}

\author{
Barbara Klink $^{\mathrm{a}, *}$, Ben Schlingelhof ${ }^{\mathrm{a}}$, Martin Klink ${ }^{\mathrm{a}, * *}$, Karen Stout-Weider ${ }^{\mathrm{a}, * * *}$, \\ Stephan Patt ${ }^{\mathrm{b}}$ and Evelin Schrock ${ }^{\mathrm{a}}$ \\ ${ }^{a}$ Institut für Klinische Genetik, Medizinische Fakultät Carl Gustav Carus, Technische Universität Dresden, \\ Dresden, Germany \\ ${ }^{\mathrm{b}}$ Institut für Pathologie, Medizinische Fakultät, Friedrich-Schiller Universität Jena, Jena, Germany
}

\begin{abstract}
Background: Glioblastomas are the most common and most malignant brain tumors in adults. A small subgroup of glioblastomas contains areas with histological features of oligodendroglial differentiation (GBMO). Our objective was to genetically characterize the oligodendroglial and the astrocytic parts of GBMOs and correlate morphologic and genetic features with clinical data.

Methods: The oligodendroglial and the "classic" glioblastoma parts of 13 GBMO were analyzed separately by interphase fluorescence in situ hybridization (FISH) on paraffin sections using a custom probe set (regions 1p, 1q, 7q, 10q, 17p, 19q, cen18, 21q) and by comparative genomic hybridization (CGH) of microdissected paraffin embedded tumor tissue.

Results: We identified four distinct genetic subtypes in 13 GBMOs: an "astrocytic" subtype (9/13) characterized by +7/-10; an "oligodendroglial" subtype with $-1 \mathrm{p} /-19 \mathrm{q}(1 / 13)$; an "intermediate" subtype showing $+7 /-1 \mathrm{p}(1 / 13)$, and an "other" subtype having none of the former aberrations typical for gliomas $(2 / 13)$. The different histological tumor parts of GBMO revealed common genetic changes in all tumors and showed additional aberrations specific for each part.

Conclusion: Our findings demonstrate the monoclonal origin of GBMO followed by the development of the astrocytic and oligodendroglial components. The diagnostic determination of the genetic signatures may allow for a better prognostication of the patients.
\end{abstract}

Keywords: Glioblastoma, oligodendroglial component, GBMO, genetics, CGH, Interphase-FISH, genetic subclassification

\section{Introduction}

Gliomas are the most frequent primary brain tumors of adults. The World Health Organization (WHO) classification divides gliomas into three main subgroups, i.e., astrocytomas, oligodendrogliomas and mixed oligoastrocytomas, and differentiates between

\footnotetext{
*Corresponding author: Barbara Klink, Institute of Clinical Genetics, University of Technology, Dresden, Fetscherstr. 74, D-01307 Dresden, Germany. Tel.: +49 351458 2894; Fax: +49 351458 6337; E-mail: barbara.klink@tu-dresden.de.

${ }^{* *}$ Current address: Deutscher Wetterdienst, 14473 Potsdam, Germany.

*** Current address: Charité-Universitätsmedizin Berlin, Institut für Medizinische Genetik, Augustenburger Platz 1, 13353 Berlin, Germany.
}

four malignancy grades (WHO grades I-IV). Because phenotypic heterogeneity within these tumors is quite frequent, the histopathologic examination yields differing results, even when performed by experienced pathologists. Especially the differentiation between glioblastoma multiforme and anaplastic glioma (WHO grades IV and III) with either oligodendroglial, astrocytic or both features could be very difficult $[7,13,53]$. Moreover, the clinical outcome is often not predictable, which may reflect biological heterogeneity within each of the tumor groups. Research during the last years has thus been focused on a more accurate characterization of these tumors including the identification of new prognostic markers in order to supply and complement histology-based classification. 
More than $50 \%$ of all gliomas belong to the glioblastoma multiforme subtype (GBM), which is one of the most malignant tumors of adults (WHO grade IV) [38]. The prognosis of GBM is very poor with a median survival of approximately one year [8,31]. To date, many genetic aberrations have been identified, which are commonly found in GBM, e.g., complete or partial gain of chromosome 7 , loss or partial deletion of chromosome 10, PTEN mutations, amplification of EGFR, CDKN2A (p16) deletion and TP53 mutation, etc. $[3,32,38,40]$. However, none of these genetic aberrations has so far been implemented as a diagnostic or prognostic marker in routine neuropathology. In contrast to astrocytic tumors including GBM, oligodendrogliomas, which account for 5-18\% of all gliomas $[38,51]$ show a better prognosis and increased responsiveness to chemotherapy $[5,6,50,54]$. Typically, oligodendrogliomas are associated with the combined loss of chromosome arms $1 p$ and $19 q[12,45]$.

Interestingly, a small subgroup of GBM contains areas with histological features of oligodendroglial differentiation $[2,9,15]$. They are referred to as oligoastrocytoma grade IV or glioblastomas with oligodendroglial component (GBMO) [15,28].

Because only a few molecular studies of these particular glioblastoma cases with an oligodendroglial component have been performed, it remains also uncertain, whether an oligodendroglial component in a glioblastoma renders it less aggressive and could thus function as a predictive factor for the clinical outcome of the patient $[13,15,21,28,56]$. Some evidence has been reported indicating that GBMO are associated with prolonged survival $[16,28,31]$. The new edition of the WHO classification 2007 includes glioblastomas with oligodendroglial components (GBMO) as a distinctive variant of GBM [22]. However, definite diagnostic criteria do not exist. Therefore, it remains to be determined if the different phenotypic features are associated with special genetic changes.

The aim of our study was thus to genetically characterize GBM cases with and without an oligodendroglial component and correlate their particular histological and genetic features with the clinical follow-up (survival) in order to identify diagnostic and prognostic markers in GBMO.

\section{Materials and methods}

\subsection{Patients and tumor samples}

GBM cases from the archive of the Institute of Pathology, Jena, Germany, originally classified according to the WHO 2000 criteria as glioblastomas (WHO grade IV) [23], were reevaluated in order to identify distinctive histological features of oligodendroglial appearance. We found 13 GBMOs and among them were eight, which revealed areas with typical clear cells (honeycomb appearance) in H\&E sections as well as cytoplasmic GFAP-negativity. We subclassified them as GBMO with honeycomb appearance (GBMO-H). The remaining five tumors showed highly cellular areas consisting of round, uniform, oligodendroglial-like cells which, however, were completely GFAP-negative and lacked the typical honeycomb or clear-cell appearance in $\mathrm{H} \& \mathrm{E}$ sections; they were named GBMO with round cells (GBMO-R). All 13 GBMO also consisted of areas with "classic" glioblastoma features in terms of astrocytic differentiation. Distinct features such as necrosis, vascular proliferation and increased mitotic and proliferation activity indicated the high malignancy potential. These characteristics were important to us for the differentiation between anaplastic oligoastrocytomas and anaplastic oligodendrogliomas. An example of the astrocytic and oligodendroglial parts of one GBMO-H and one GBMO-R is provided in Fig. 1.

As a control group we retrieved an unselected independent series of ten "classic" GBM without any special histological features, i.e., without an oligodendroglial component. Furthermore, we used three typical oligodendrogliomas without astrocytic features, respectively, as examples for oligodendroglial differentiation. The tumors were classified as oligodendrogliomas according to WHO grade II.

The 23 GBM cases (13 GBMO and 10 "classic" GBM) were collected from 12 females and 11 males; the median age at diagnosis was 59 years. Surgery was performed between 1997-2002 either at the Department of Neurosurgery, Friedrich-Schiller University, Jena, or at the Neurosurgery Clinics in Bad Berka, Erfurt, and Halle, Germany. 19 out of 23 patients with glioblastoma received adjuvant radiotherapy, and nine were treated with additional adjuvant chemotherapy, such as temozolomide or nimustide (ACNU) or the combination of procarbazine, lomustine and vincristine (Table 1).

\subsection{Selection of tissue components and microdissection}

For each GBMO case, one to two paraffin-embedded tumor blocks were selected, which included an "oligodendroglial" and an "astrocytic" component. Paraffin blocks were cut according to a specific scheme to make sure that the sections included the areas of interest (Fig. 2). The first section was stained using H\&E for 

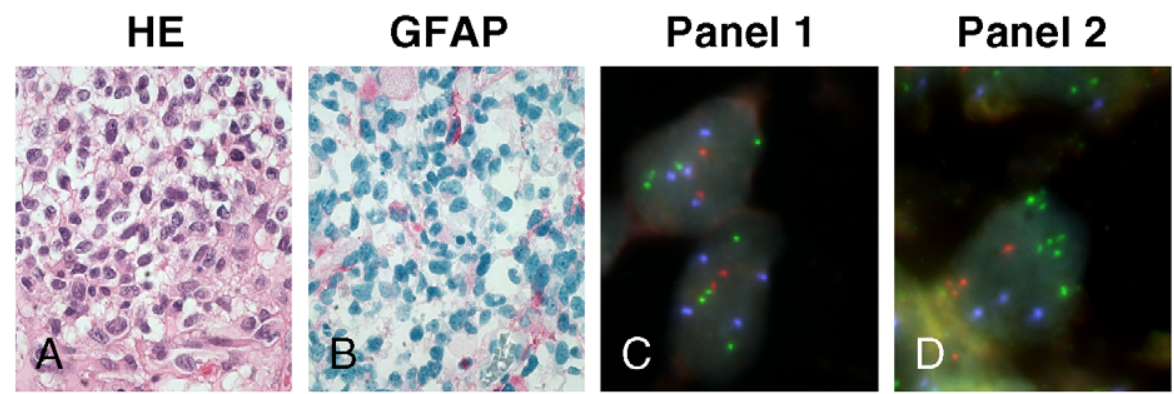

Panel 3
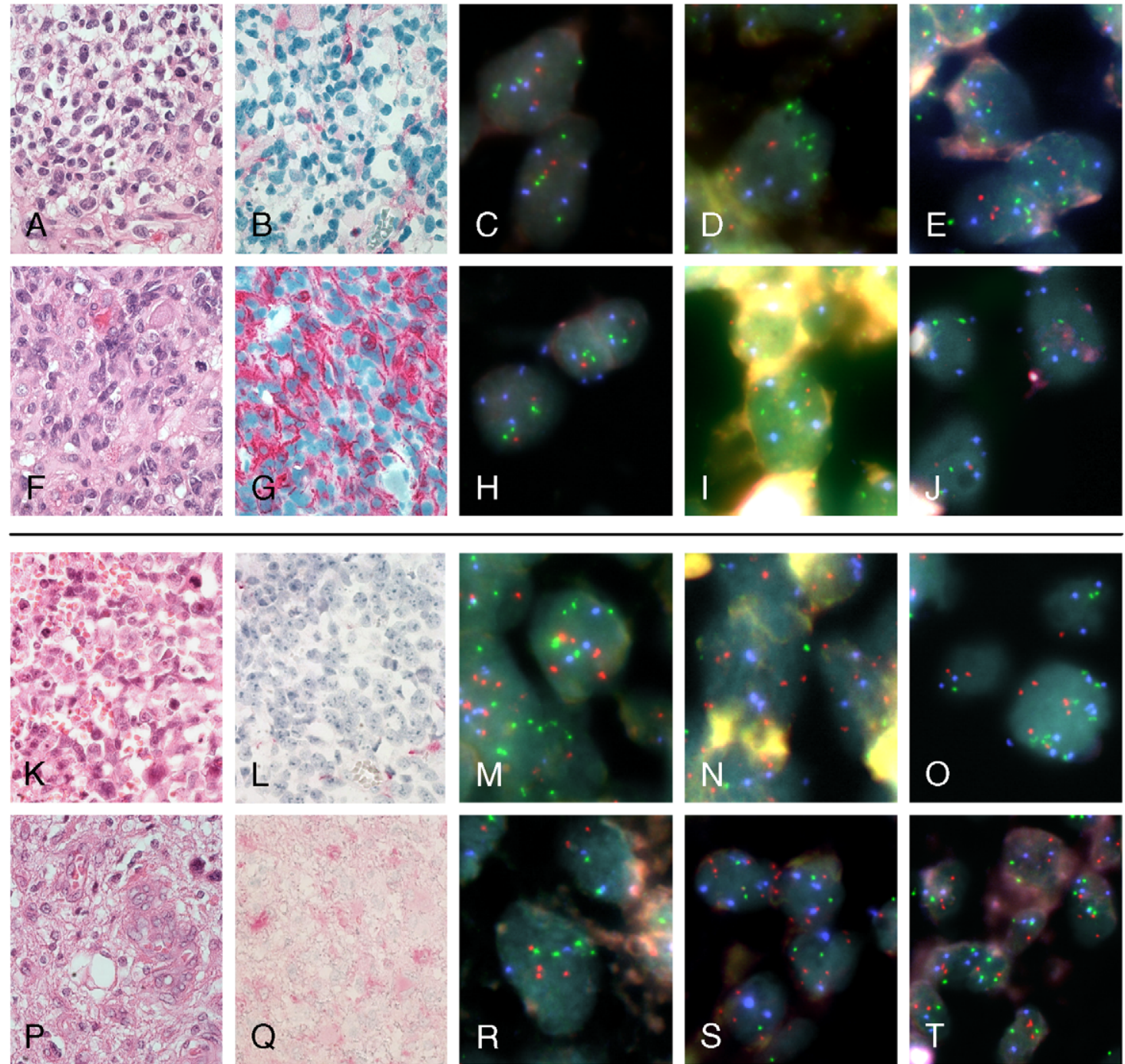

Fig. 1. Histological appearance and Interphase-FISH results of the oligodendroglial and astrocytic parts of one GBMO-H and one GBMO-R exemplifying the principle approach. First row: Oligodendroglial component of one GBMO-H (ID11) with typical clear cells and honeycomb appearance in the H\&E-stain $(\times 200)(A)$ and lack of GFAP in the immunohistochemistry $(\times 200)(B)$. Interphase-FISH $(\times 400)$ revealed triploid tumor cells (D: 3 blue signals for cen18) with $+1 \mathrm{p}(\mathrm{C}, \mathrm{E}: 4$ green signals), +1q (E: 4 blue signals), +7q (D: 4 red signals), +10q (D: 5 green signals), $+21 \mathrm{q}$ (C: 4 blue signals) and $-19 \mathrm{q}$ (C: 2 red signals). The "classic" glioblastoma part of the same tumor (second row) showed astrocytic like cells in the H\&E-stain (F), which were mostly GFAP-positive (G). The tumor cells had $+1 \mathrm{q}$ (J: 4 blue signals), $+21 \mathrm{q}$ (H: 4 blue signals), $-17 \mathrm{p}$ (J: 2 red signals), $-19 q$ (H: 2 red signals), but a normal 1p (H: 2-3 green signals), 7q and 10q (I: 3 green and red signals) in most tumor cells. In addition, the cells showed +cen18 (I: 4 blue signals). K-T give an example for one GBMO-R (ID9): The oligodendroglial part (third row) consisted of round, uniform, GFAP-negative tumor cells $(\mathrm{K}, \mathrm{L})$. Most nuclei were triploid (M, N: 3 blue signals for $21 \mathrm{q}$ and cen 18$)$ with $+1 \mathrm{p}$ $(\mathrm{M}, \mathrm{O}: 5$ green signals), $+1 \mathrm{q}(\mathrm{O}: 5$ blue signals $),+7 \mathrm{q}(\mathrm{N}: 5$ red signals $),+17 \mathrm{p}(\mathrm{O}: 5$ red signals $),+19 \mathrm{q}(\mathrm{M}: 5$ red signals) and $-10 \mathrm{q}(\mathrm{N}: 1$ green signal). In contrast, the astrocytic part of the same tumor (fourth row) showing classical GBM features (including vascular proliferation) in the H\&E-stain (P) and GFAP-positivity (Q) consisted of diploid nuclei (R: 2 blue signals for $21 \mathrm{q})$ with $+1 \mathrm{p}(\mathrm{R}, \mathrm{T}: 4$ green signals), $+1 \mathrm{q}(\mathrm{T}$ : $3-4$ blue signals), $+7 q$ (S: 4 red signals), $+17 p$ (T: 3 red signals), $+19 q$ (R: 4 red signals) and $-10 q$ (S: 1 green signal). Recognize the different cell clones in one tumor area: For example, + cen 18 and $-10 \mathrm{q}$ was present only in a proportion of tumor cells (S: 2 or 3 blue signals, 1 or 2 green signals). Also a differing proportion of cells showed no genetic changes as it is seen, for example, in $\mathrm{R}$ and $\mathrm{T}$ (each 2 signals for the DNA-probes in green, red and blue). 
Table 1

Clinical characteristics of patients with GBMO and GBM

\begin{tabular}{|c|c|c|c|c|c|}
\hline & GBMO-H $(n=8)$ & GBMO-R $(n=5)$ & GBMO $(\text { total })^{\mathrm{a}}(n=13)$ & $\operatorname{GBM}(n=10)$ & $p$-value ${ }^{b}$ \\
\hline \multicolumn{6}{|l|}{ Age in years } \\
\hline Median (range) & $55(42-72)$ & $51(46-70)$ & $52(42-72)$ & $67.5(46-75)$ & \\
\hline Mean $(95 \%$ CI) & $55.13(47-63)$ & $55.80(42-70)$ & $55.38(49-61)$ & $63.80(56-72)$ & $0.072^{\mathrm{c}}$ \\
\hline \multicolumn{6}{|l|}{ Sex } \\
\hline Female & 6 & 2 & 8 & 4 & $0.4^{\mathrm{d}}$ \\
\hline \multicolumn{6}{|l|}{ Radiation } \\
\hline Yes & 6 & 4 & 10 & 9 & $0.6^{\mathrm{d}}$ \\
\hline \multicolumn{6}{|l|}{ Chemotherapy } \\
\hline Yes & 4 & 2 & 6 & 3 & $0.67^{\mathrm{d}}$ \\
\hline \multicolumn{6}{|l|}{ Survival in days } \\
\hline Mean $(95 \%$ CI) & $386(206-566)$ & $430(327-533)$ & $404(284-524)$ & $282(196-368)$ & \\
\hline
\end{tabular}

Notes: ${ }^{\mathrm{a}} \mathrm{GBMO}$ (total) consist of GBMO-H and GBMO-R; ${ }^{b}$ Comparison of two groups: GBMO (total) vs. GBM, for age, sex, radiation and chemotherapy. $p$-values are two-sided; ${ }^{\mathrm{c}} \mathrm{Mann}-$ Whitney $U$-test; ${ }^{\mathrm{d}}$ Fishers exact test. Abbreviations: GBMO glioblastoma with oligodendroglial component; GBMO-H - GBMO with honeycomb appearance; GBMO-R - GBMO with round, oligodendroglia-like tumor cells; GBM - "classic" glioblastoma; $n$ - number of cases.

obtaining the histopathologic diagnosis. Importantly for the present study, FISH-analyses were performed using four to six $10 \mu \mathrm{m}$ sections immediately adjacent to the first H\&E-stained slide to make sure that the different tissue components were indeed included. The optimal thickness of $10 \mu \mathrm{m}$ was ascertained by testing $4,6,8,10$ and $12 \mu \mathrm{m}$ sections in order to minimize the amount of truncated nuclei while still allowing enumeration of the FISH-signals (data not shown). DNA was extracted for the $\mathrm{CGH}$ analysis from subsequent two to five $10 \mu \mathrm{m}$ sections. Here, oligodendroglial parts of the tumors were treated separately from the region that appeared to be the astrocytic part of the tumor using needle microdissection. The last section was again stained with H\&E in order to confirm that all the analyses were performed using tumor material including all intended different histological parts.

\subsection{DNA extraction}

DNA preparations of bacterial artificial chromosomes (BACs) for FISH probes and peripheral blood leucocytes as control-DNA for $\mathrm{CGH}$ analysis were carried out according to standard protocols. Tumor-DNA was extracted from formalin-fixed paraffin-embedded material after deparaffination and treatment with $1 \mathrm{M}$ NaSCN overnight using the QIAamp DNA Mini Kit (Qiagen, Hilden, Germany).

\subsection{Fluorescence in situ hybridization (FISH)}

FISH probes and probe labelling. Three probe panels were designed based on data from the literature to include genomic regions of interest that are typically gained or lost in gliomas and were thus of potential use as diagnostic markers, i.e., regions on chromosome arms $1 p$ and $19 q$ as markers for oligodendrogliomas [45], and regions on chromosome arms $7 \mathrm{q}, 10 \mathrm{q}$ and the tumor suppressor gene TP53 on 17p for astrocytomas and/or GBM, respectively [3,26,38, 48]. Each panel also contained one additional control probe to detect the ploidy levels of the tumor cells (1q, centromere of chromosome 18 (CEP18) and 21q). This was important to exclude false negative losses as well as false positive gains due to tri-, tetra- or polyploidy. FISH probes were generated by combining two to three overlapping BACs per probe provided by the Deutsches Ressourcenzentrum für Genomforschung (Berlin, Germany) or the CITB database (Research Genetics, Invitrogen, Karlsruhe, Germany) and one centromeric probe as follows [29]: Panel 1 contained BACs RP11-62m23, RP5-1092a11, RP5897i12 on 1p36.3 (TP73); RP11-492p7, RP11-613p20, RP11-183o14 on 19q13.3 (p190-A); and RP11-31b6, RP11-22d1, RP11-61a21 on 21q11.2; Panel 2 consisted of BACs RP11-380g5, RP11-765c10, RP11$165 \mathrm{~m} 8$ on $10 \mathrm{q} 23.3$ (PTEN); CTB-300c3, CTB-13n12 


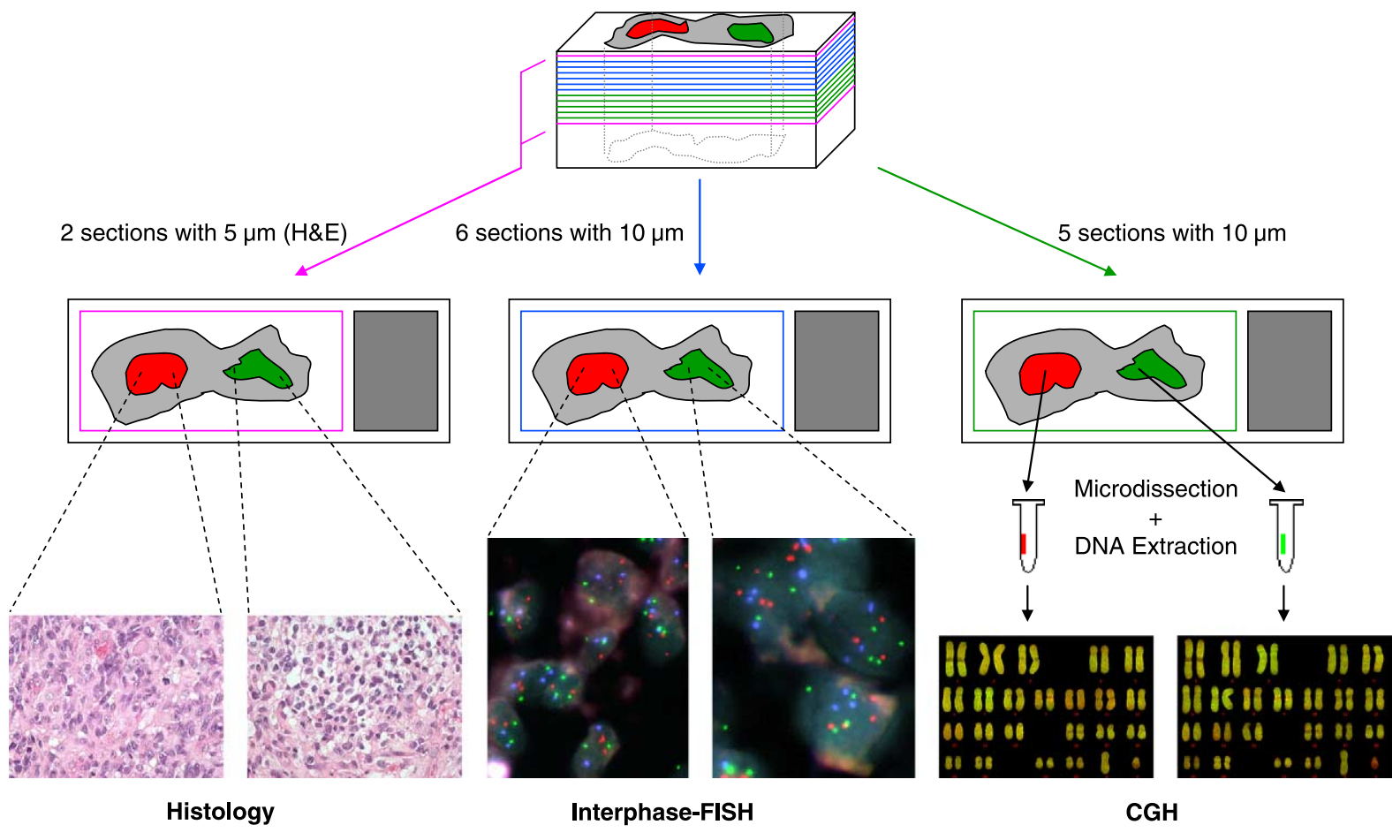

Fig. 2. Overview of the strategy of the project. Paraffin-embedded tumor material (indicated in grey on the glass slides) was cut in the following order: First one H\&E-stained section (violet arrow and lines) was made to check if the two different tumor parts, the "astrocytic" (indicated in red), and the "oligodendroglial" (indicated in green), were still available. Hereupon six 10- $\mu$ m-thick sections (blue arrow and lines) were cut for Interphase-FISH and the two different tumor areas according to the histology were evaluated separately. Five consecutive 10- $\mu$ m-thick sections (green arrow and lines) were prepared for DNA extraction for the CGH analysis. "Astrocytic" and "oligodendroglial" tumor parts were microdissected with a needle under a light-microscope and DNA was extracted separately. Finally, one H\&E-stained section was evaluated again to control that both tumor parts were still existent.

on 7q31 (MET) and an alphasatellite DNA probe for the centromere of chromosome 18 (CEP18); Panel 3 contained BACs RP11-1116m11, RP11-278j17, RP11$296 \mathrm{a} 18$ on $1 \mathrm{p} 32$ (CDKN2C); RP11-199f11, RP111d5 on 17p13.1 (TP53); and RP11-148k15, RP1123i7, RP11-155f3 on 1q32.1 (GAC1). Probes were labeled via Nick-translation using Biotin-16-dUTP (Roche, Mannheim, Germany) for 1p36.3, 10q23.3 and 1p32, Tamra-dUTP (Applied Biosystems, Darmstadt, Germany) for $19 \mathrm{q} 13.3,7 \mathrm{q} 31$ and $17 \mathrm{p} 13.1$ and Digoxygenin-11-dUTP (Boehringer, Ingelheim Germany) for 21q11.2, CEP18 and 1q32.

In situ hybridization. After deparaffination, slides were pretreated with $0.2 \mathrm{~N} \mathrm{HCL}$ for $60 \mathrm{~min}$ followed by $1 \mathrm{M} \mathrm{NaSCN}$ overnight at $37^{\circ} \mathrm{C}$. Pepsin digestion $(2 \mathrm{mg} / \mathrm{ml}$ in $0.9 \% \mathrm{NaCl} \mathrm{pH} 1.5)$ took place at $37^{\circ} \mathrm{C}$ for $5-40 \mathrm{~min}$; the optimal time was determined for each slide individually by visual examination. RNAse digestion was added followed by fixation using $1 \%$ formaldehyde. Slides were denatured in $70 \%$ formamide, $2 \times \mathrm{SSC}$ for $3 \mathrm{~min}$ at $74^{\circ} \mathrm{C}$ two times. After hybridization over two nights by $37^{\circ} \mathrm{C}$, biotinylated probes were visualized with FITC connected to avidin (Jackson ImmunoResearch, Suffolk, UK) and digoxigenin-labeled probes were detected using mouse-anti-Digoxin (Jackson ImmunoResearch, Suffolk, UK) followed by a Cy5-goat-anti-mouse antibody (Jackson ImmunoResearch, Suffolk, UK). The slides were counterstained with DAPI and embedded in an antifade solution [1,49].

Signal enumeration/Scoring criteria. Ten to $15 \mathrm{mul}-$ tifocus images per specimen and region were acquired using the software CW4000, V3.0 (Leica Microsystems $\mathrm{GmbH}$, Cambridge, UK) with a DMRA epifluorescence microscope (Leica, Wetzlar, Germany) equipped with custom optical filters for DAPI, FITC, Tamra and Cy5 (Chroma Technology Corporation, Rockingham, NC, USA) and connected to a Quantix CCD camera (Photometrics, Roper Bioscience Systems, Tucson, AZ, USA). Signal enumeration was per- 

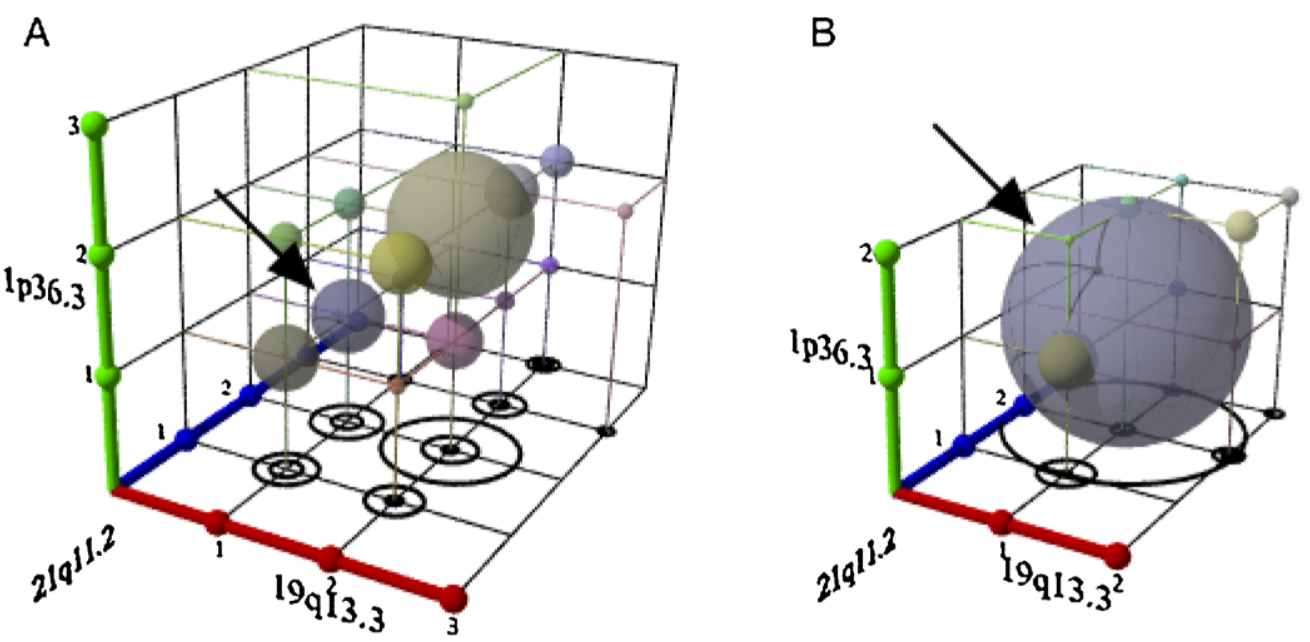

Fig. 3. Representation of the different tumor cell clones in a 3D-diagram using the dedicated software, which was developed for the present study. The axes of the diagram correspond to the numbers of signals per fluorescent probe. Spheres at the corresponding coordinates of the diagram demonstrate similar cell clones. The size of the sphere is defined by the frequency of the cell clone. The example shows Interphase-FISH results for the astrocytic (A) and the oligodendroglial component (B) of the same GBMO-H using panel 1 (green fluorescence: 1p36, red fluorescence: $19 q 13.3$, blue fluorescence: $21 q 11.2$ ). Our analysis revealed the combination $-1 p /-19 q$ (the arrows indicate the cell clones with one signal for $1 \mathrm{p}$ and $19 \mathrm{q}$ and two signals for $21 \mathrm{q}$ ) in most of the cells in the oligodendroglial part (B) but only in a few cells of the astrocytic part (A). In the astrocytic part, most cells had a normal $1 \mathrm{p}$ and $19 \mathrm{q}$ signal count (A: biggest sphere).

formed on these digital images by two independent observers on 200 non-overlapping nuclei. Gains and losses were scored if there were more or, respectively, fewer signals compared to the signals of the control probe and were interpreted as deletion when more than $30 \%$ of the nuclei harbored the alteration and as gain when more than $20 \%$ of nuclei were affected. Cutoff levels were determined on paraffin sections of normal brain tissue and were applied in accordance with other studies on paraffin sections [33,44,58].

Software-development. We designed a dedicated computer program to present the information obtained from the Interphase-FISH analysis in a 3-dimensional diagram in order to compare the results for the astrocytic and the oligodendroglial tumor parts (Fig. 3). The software consists of a small python-script (version 2.2.3, Python Software Foundation, Hampton, VA, USA) that uses the Persistence of Vision raytracer (version 3.5, Persistence of Vision Raytracer Pty. Ltd., Williamstown, Australia) to produce the visualizations.

The three axes of the diagram correspond to the three different signals/probes per panel and cell, so every cell clone was defined by three coordinates and illustrated as a sphere. The frequency of the cell clones was visualized by the size of the sphere. Using this software, the number of cells with identical signal counts for all three probes within one panel was ob- tained for each of the three panels per tumor. This allowed us to gain detailed information on the composition of the heterogenetic tumors with respect to their different cell clones and the respective genetic changes including the great variability in ploidy within the same tumor areas.

\subsection{Comparative genomic hybridization}

Tumor and control DNA were amplified and labelled via ligation mediated PCR as previously described by Klein et al. [24]. Chromosome CGH was performed as described in detail elsewhere [48,49]. For image capture and processing of CGH data, the Leica CW 4000 System (Leica, Wetzlar, Germany) was used.

\subsection{Statistics}

All statistical analyses were performed using SPSS software (versions 12.0 and 15.0, SPSS GmbH, München, Germany). Fisher's exact test or Chi-square test was employed for comparison of proportions. Comparison of Age was done using the Mann-Whitney $U$ test. Overall survival (OS) was defined as the time period from the date of first surgery until the death of the patient and censored at the time of the last follow up. Survival function curves were calculated with the Kaplan-Meier method. Survival time was compared 
among patient subsets using log-rank tests and the Cox proportional hazard model for univariate and multivariate analyses. A $p$-value of $<0.05$ was considered statistically significant. All reported $p$-values are two-sided.

\section{Results}

\subsection{Clinics}

The 13 patients with GBMO ( 8 females, 5 males) had a median age of 52 years (range 42-72 years) compared to a median age of 67.5 years (range 4675 years) in the ten patients with "classic" GBM (4 females, 6 males). $76.9 \%(10 / 13)$ of the patients with GBMO and $90 \%(9 / 10)$ of the patients with GBM received radiotherapy and $46.2 \%(6 / 10)$ respectively $30 \%(3 / 10)$ received chemotherapy. There were no significant differences between patients with GBM or GBMO for age, sex and frequency of radiation or chemotherapy; however, patients with GBMO tend to be younger than patients with "classic" GBM. The clinical data of the glioblastoma patients compared to the different histological subtypes are summarized in Table 1.

\subsection{Molecular cytogenetic analyses using Interphase-FISH and chromosome CGH}

A total of 26 gliomas, 13 GBMO, 10 "classic" GBM and 3 oligodendrogliomas were investigated using Interphase-FISH analysis and 12 of the 13 GBMO were studied by chromosome $\mathrm{CGH}$ analysis. The tumor material was processed following a dedicated scheme (see Section 2 and Fig. 2). In ten of the 13 GBMO, the paraffin block still contained the two different histological parts after all sections were cut as described. Therefore, chromosome CGH results could be evaluated separately for the astrocytic and oligodendroglial parts. In three GBMO only one component was left for investigation in the bottom sections.

The most frequent genetic aberrations found in the 23 GBM (13 GBMO and 10 "classic" GBM) with both methods were the gain of chromosome $7(22 / 23)$ and loss of chromosome $10(19 / 23)$ resulting in a combined $+7 /-10$ status in 19 out of 23 cases. Gains of chromosome arms $19 q(9 / 23)$ and $1 \mathrm{q}(9 / 23)$ and losses of $17 \mathrm{p}(6 / 23)$ and $19 q(6 / 23)$ were also common. The most frequently identified amplification involved the EGFR gene locus on $7 \mathrm{p} 12(5 / 12)$. The Interphase-
FISH and CGH results of all GBM and GBMO were summarized in Table 2.

In contrast, all three oligodendrogliomas showed the combined loss of 1p/19q using Interphase-FISH.

FISH-and CGH-analyses distinguished four genetic subtypes. Based on their different genetic make-up we could clearly distinguish four subtypes among the 13 GMBO: (i) tumors showing the combined gain of chromosome 7 and loss of chromosome 10 belong to the "astrocytic" subtype (9/13); (ii) the "oligodendroglial" subtype was characterized by the combined loss of $1 p$ and $19 q$ (without the gain of chromosome 7 and loss of chromosome 10) (1/13); (iii) tumors with "intermediate" subtype showed a combination of the genetic changes of the "astrocytic" and "oligodendroglial" subtypes, i.e. gain of chromosome 7 and loss of chromosome arm 1p (1/13); (iv) two GBMO, however, had none of the previous aberrations typical for gliomas and were summarized in the genetic subtype "others". They demonstrated a gain on 10q23, a gain of the short arm of chromosome 9 and the loss of material of chromosome 16. These aberrations were not found in any tumor of the other three genetic subtypes stated above.

\subsection{Correlation between histological features and genetic subtypes}

All five GBMO with round, oligodendroglial-like cells (GBMO-R) belonged to the "astrocytic" subtype with a $+7 /-10$ genotype. In contrast, the GBMO-H tumors were heterogeneous, the "astrocytic" subtype was found in only four of the eight cases $(50 \%)$. The other four GBMO-Hs were either associated with the "oligodendroglial", "intermediate" or "other" genetic subtypes, despite their phenotypic similar appearance (compare Fig. 4).

All "classic" GBM (10/10) presented with the combination $+7 /-10$ and therefore corresponded also genetically to the "astrocytic" subtype, whereas all three oligodendroglioma demonstrated the " $-1 \mathrm{p} /-19 \mathrm{q}$ " genotype.

The genetic subtype "astrocytic" was therefore found in "classic" GBM, in GBMO-H as well as in GBMO-R, but never in oligodendroglioma. The "oligodendroglial" subtype was seen in oligodendroglioma and GBMO-H, whereas the genetic subtypes "intermediate" or "other" were exclusively found in GBMO-H.

When looking at the histological appearance first, a genetic subtype other than the "astrocytic" subtype 
Table 2

Interphase-FISH and CGH results of GBMOs and GBMs

\begin{tabular}{|c|c|c|c|c|c|c|c|c|c|c|c|c|c|c|}
\hline \multirow[t]{2}{*}{ ID } & \multirow[t]{2}{*}{ Histology } & \multirow{2}{*}{$\begin{array}{l}\text { Tumor } \\
\text { component }\end{array}$} & \multicolumn{10}{|c|}{ Interphase-FISH } & \multicolumn{2}{|c|}{ Comparative genomic hybridization (CGH) } \\
\hline & & & $\begin{array}{l}\text { ڤn. } \\
\stackrel{\overbrace{}}{=} \\
=\end{array}$ & $\cong$ & $\begin{array}{l}\bar{i} \\
\stackrel{\sim}{\Xi}\end{array}$ & $\frac{\sim}{\frac{N}{2}}$ & 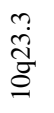 & $\begin{array}{l}\vec{m} \\
\stackrel{2}{a}\end{array}$ & $\stackrel{\infty}{\rightleftarrows}$ & $\frac{m}{\stackrel{m}{\sigma}}$ & $\frac{\stackrel{N}{\Xi}}{\stackrel{\Xi}{\sim}}$ & $\frac{3}{0}$ & Loss & Gain \\
\hline \multirow[t]{2}{*}{1} & GBMO-H & oligo & - & $\mathrm{n}$ & $\mathrm{n}$ & + & $\mathrm{n}$ & $\mathrm{n}$ & $\mathrm{n}$ & $\mathrm{n}$ & $\mathrm{n}$ & $\mathrm{d}$ & $\begin{array}{l}\text { 1p36, 8p12-pter, 13q14-21, 14, } \\
15 q 15,19, Y\end{array}$ & $3,6 \mathrm{q}, 7$, amp7p21-15, 9 \\
\hline & & astrocytic & - & $\mathrm{n}$ & $\mathrm{n}$ & + & $\mathrm{n}$ & $\mathrm{n}$ & $\mathrm{n}$ & $\mathrm{n}$ & $\mathrm{n}$ & $\mathrm{d}$ & 1p36, 8p12-pter, 14, 19, Y & $3,6 \mathrm{q}, 7$, amp7p21-15, 9, 18q \\
\hline \multirow[t]{2}{*}{2} & GBMO-H & oligo & + & + & + & + & - & + & - & $\mathrm{n}$ & $\mathrm{n}$ & $\mathrm{p}$ & $2,4,10,13,14,15,18,20,22$ & $1,6,7,9,12$ pter-q21, $17, \mathrm{X}$ \\
\hline & & astrocytic & + & + & + & + & - & $\mathrm{n}$ & - & - & + & $\mathrm{p}$ & $2,6 \mathrm{q} 15$-qter, $10,11,14,18,19,22$ & $\begin{array}{l}\text { 1,3,7, amp7p12, 9q, 13, 15, 20p, } \\
\text { amp20p12, amp21q-21, X }\end{array}$ \\
\hline \multirow[t]{2}{*}{3} & GBMO-H & oligo & + & + & + & + & + & $\mathrm{n}$ & + & $\mathrm{n}$ & $\mathrm{n}$ & $\mathrm{p}$ & $\mathrm{x}$ & $\begin{array}{l}\text { 1q, amp2p23, 3q24-qter, 7, 9p, } \\
\text { 17q21-qter, 18q }\end{array}$ \\
\hline & & astrocytic & + & + & + & $\mathrm{n}$ & $\mathrm{n}$ & - & + & - & $\mathrm{n}$ & $\mathrm{p}$ & 10, 12p12-pter, 16p, 17p, 19, 22 & $\begin{array}{l}3 \mathrm{q} 24-26,4, \text { amp4q12, 6q, 8q21-23, } \\
9 \mathrm{p}, \text { amp11q14-22, 18q }\end{array}$ \\
\hline \multirow[t]{2}{*}{4} & GBMO-H & oligo & & & & & & & & & & & & \\
\hline & & astrocytic & $\mathrm{n}$ & $\mathrm{n}$ & ++ & + & - & $\mathrm{n}$ & $\mathrm{n}$ & $\mathrm{n}$ & $\mathrm{n}$ & $\mathrm{d}$ & 10 & amp1q31-32, 7, amp12p13 \\
\hline \multirow[t]{2}{*}{5} & GBMO-R & oligo & + & + & + & + & - & $\mathrm{n}$ & $\mathrm{n}$ & $\mathrm{n}$ & $\mathrm{n}$ & $\mathrm{p}$ & $10,15, \mathrm{Y}$ & $1,3 \mathrm{p} 12$-qter, $5 \mathrm{q} 15,7$, amp $7 \mathrm{p} 12,17 \mathrm{p} 11-12$ \\
\hline & & astrocytic & + & + & + & + & - & $\mathrm{n}$ & $\mathrm{n}$ & + & $\mathrm{n}$ & $\mathrm{p}$ & 10, 11p14-pter, 15, Y & $\begin{array}{l}\text { 1,3p12-qter, 4q25-qter, 5q12-23, 7, } \\
\text { amp7p12, 13q33-qter, 17p11-12 }\end{array}$ \\
\hline \multirow[t]{2}{*}{6} & GBMO-H & oligo & - & n. d. & n. d. & $\mathrm{n}$ & $\mathrm{n}$ & n. d. & $\mathrm{n}$ & - & $\mathrm{n}$ & $\mathrm{d}$ & 1p32-pter, 17p, 19q, X & \\
\hline & & astrocytic & - & - & $\mathrm{n}$ & $\mathrm{n}$ & $\mathrm{n}$ & $\mathrm{n}$ & - & - & $\mathrm{n}$ & $\mathrm{p}$ & 1p, 3p12-qter, 4q, 6q, 9p, 13, 18, 19q & \\
\hline \multirow[t]{2}{*}{7} & GBMO-H & oligo & $\mathrm{n}$ & $\mathrm{n}$ & $\mathrm{n}$ & + & - & $\mathrm{n}$ & $\mathrm{n}$ & $\mathrm{n}$ & $\mathrm{n}$ & $\mathrm{d}$ & 5q33-qter, 6p21, 10 & 2q22-qter, 7q, amp7q11-21, 13 \\
\hline & & astrocytic & & & & & & & & & & & & \\
\hline \multirow[t]{2}{*}{8} & GBMO-R & oligo & $\mathrm{n}$ & $\mathrm{n}$ & $\mathrm{n}$ & + & - & $\mathrm{n}$ & $\mathrm{n}$ & + & $\mathrm{n}$ & $\mathrm{p}$ & $9 \mathrm{p} 13-21,10,11,22$ & $\begin{array}{l}\text { 2, 3p, 3q25-qter, 4q26-qter, } \\
\text { 7, amp18q11, 20, amp20q13, 21q22 }\end{array}$ \\
\hline & & astrocytic & $\mathrm{n}$ & $\mathrm{n}$ & $\mathrm{n}$ & + & - & $\mathrm{n}$ & $\mathrm{n}$ & $\mathrm{n}$ & $\mathrm{n}$ & $\mathrm{p}$ & $9 \mathrm{p} 13-21,10,22$ & 4q24-qter, 7,20 \\
\hline
\end{tabular}




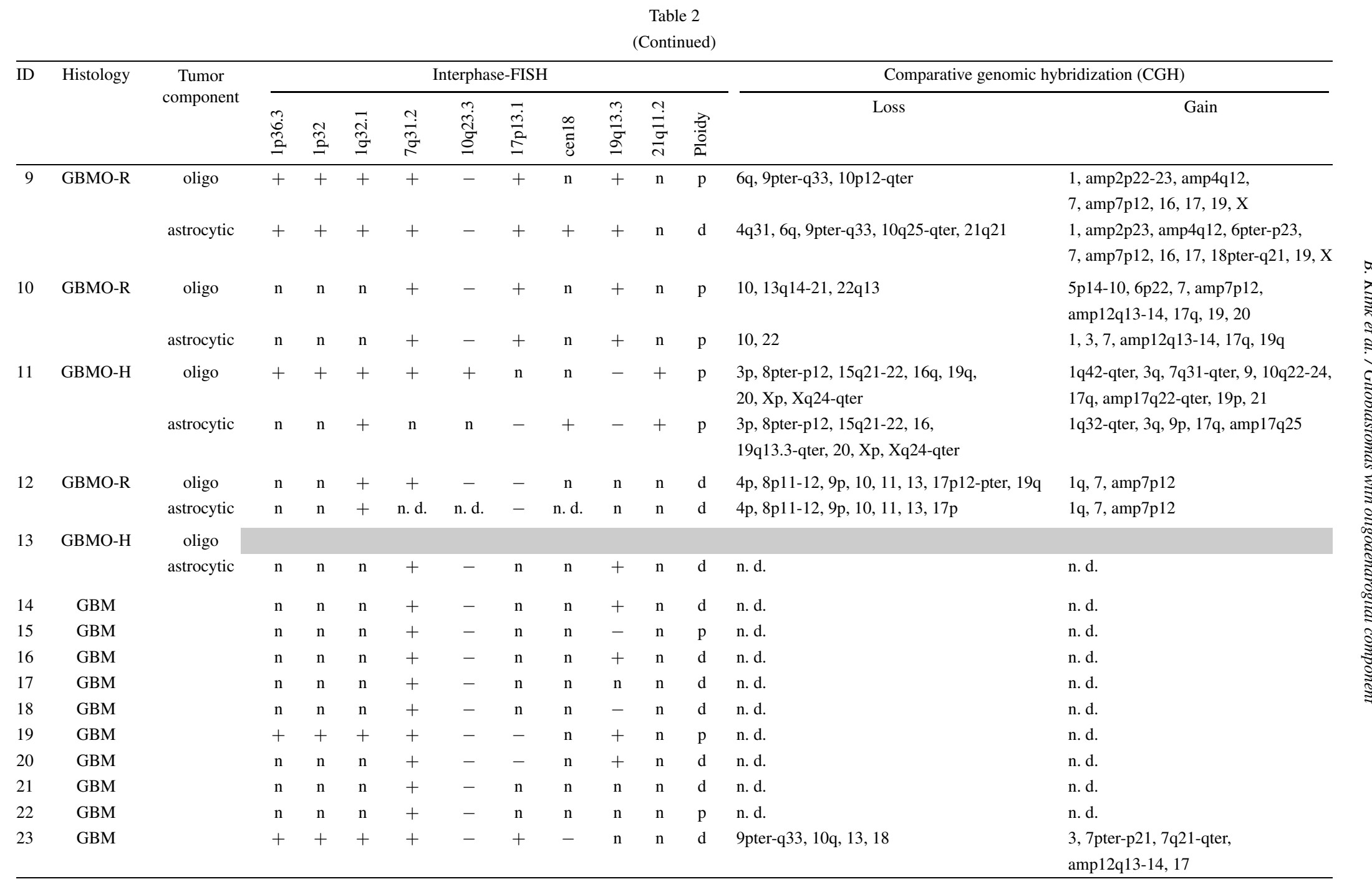

Notes: Grey: not at the paraffin block at control-H\&E for investigation. Abbreviations: GBM - "classic" glioblastoma; GBMO-H - GBM with oligodendroglial component and honeycomb appearance; GBMO-R - GBM with oligodendroglia-like, round tumor cells; + - gain; ++ - amplification; - - loss; $n$ - normal; n. d. - not done; oligo - oligodendroglial component; $\mathrm{d}$ - diploid; $\mathrm{p}$ - polyploid. 


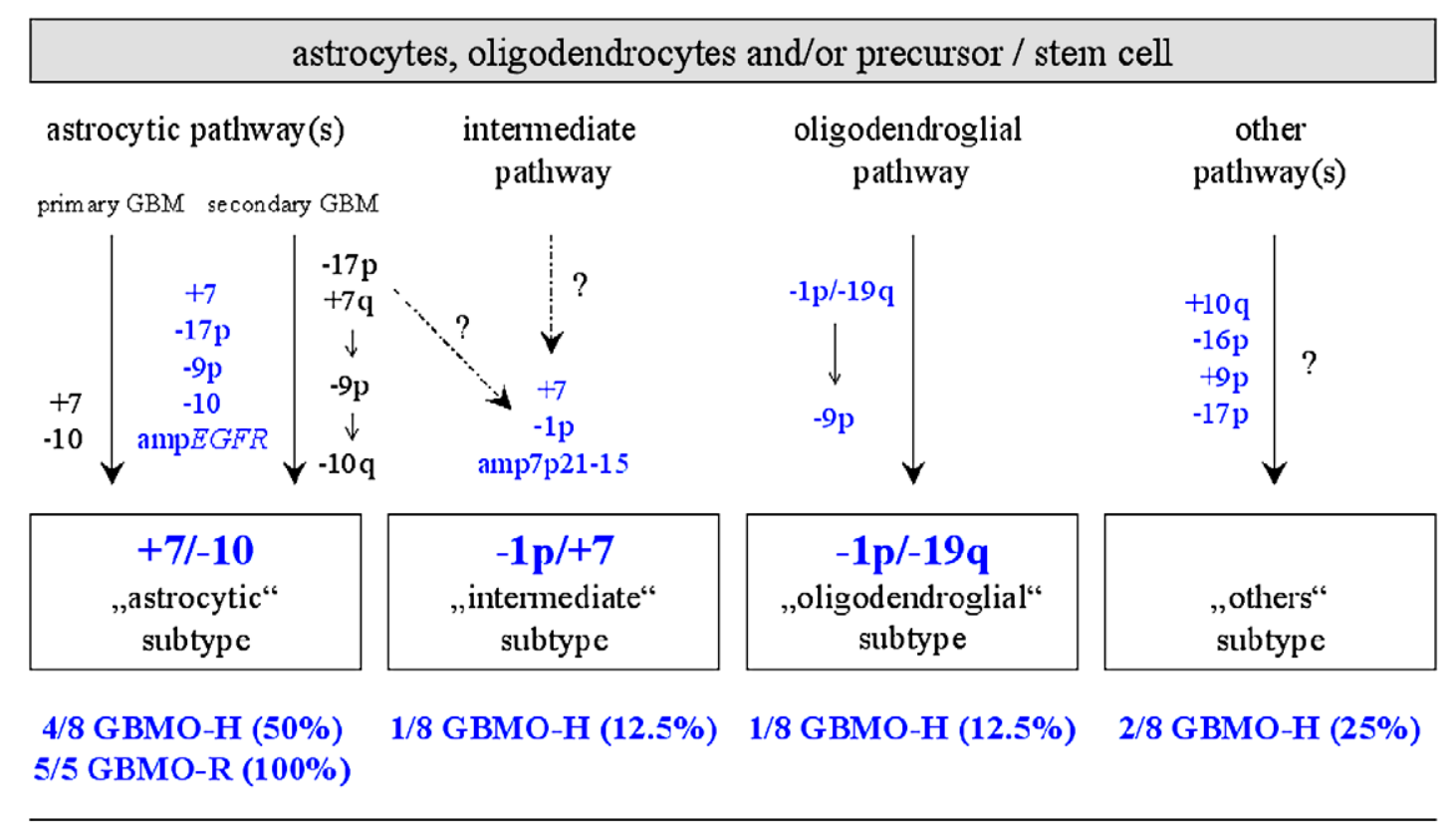

10/10 GBM (100\%)

$3 / 30(100 \%)$

Fig. 4. Genetic subtypes in GBMO. We identified four different genetic subtypes (represented in boxes) by studying 13 GBMO, indicating at least four genetic pathways leading to GBMO (an "astrocytic", "intermediate", "oligodendroglial" and "other" pathway). Genetic changes found in the GBMO were marked in blue. Abbreviations: GBMO-H - GBM with oligodendroglial component and honeycomb appearance; GBMO-R - GBM with oligodendroglia-like, round tumor cells; GBM - "classic" glioblastoma; O - oligodendroglioma.

was found only in tumors showing a histologically true honeycomb appearance of their oligodendroglial component (GBMO-H).

\subsection{Correlation between the genetic subtype and additional genetic changes}

We also identified additional genetic changes, which were associated with the different genetic subtypes. Amplifications of the EGFR locus (5/8) as well as gains of chromosome $19(5 / 9)$ were exclusively found in the "astrocytic" subtype. Other changes seen only in "astrocytic" tumors were $+6 \mathrm{p}(3 / 8),+13(3 / 8),+17 \mathrm{p}$ $(3 / 8),+20 \mathrm{p}(3 / 8)$ and $-11(3 / 8)$. Amplification of the $7 \mathrm{p} 21-15$ region, which has not yet been described in gliomas as far as we know, was only seen in the tumor with "intermediate" genetic changes. Losses of chromosome $\mathrm{X}$ and the short arm of chromosome 3 were found in the "oligodendroglial" and the "others" tumors, but not in the "astrocytic" nor the "intermediate" tumors. Interestingly, losses of the short arm of chromosome 9 were seen in "astrocytic" as well as in "oligodendroglial" tumors. Table 3 provides an overview of the genetic changes in the different genetic subtypes divided according to histology.

\subsection{Comparison of the two different histological parts in $G B M O$}

The two different parts of GBMO showed a similar appearance for their signature aberrations, but they also demonstrated additional changes, which were present either in the astrocytic or in the oligodendroglial part or in both parts (see Table 2).

The "astrocytic" GBMOs showed the following additional aberrations always in both tumor parts: $+1(3 \times),-22(3 \times),-9 \mathrm{p}(3 \times),+X(2 \times),-2$, $\operatorname{amp}(2)(\mathrm{p} 23-22), \quad \operatorname{amp}(4)(\mathrm{q} 12), \quad+5 \mathrm{q}, \quad \operatorname{amp}(7)(\mathrm{q} 12)$, $-8 \mathrm{p},+9 \mathrm{q},-14,-18,-$ Y. Both GBMO belonging to the "other" genetic subtype also had gains of chromosome 1 and the long arm of chromosome 3 each in the astrocytic and oligodendroglial part. Losses of $3 p$, $8 \mathrm{p}, 15 \mathrm{q}, 16 \mathrm{q}, 19 \mathrm{q}, 20$ and $\mathrm{X}$ as well as gain of $17 \mathrm{q}$, $18 \mathrm{q}$ and 21 were found in only one of these tumors but again in both histological parts. The "intermediate" tumor showed in both parts: $-1 \mathrm{p} 36,+3,+6 \mathrm{q}$, amp 7p15$21,-8 \mathrm{p},+9,-14,-\mathrm{Y}$.

Interestingly, the tumor in the "oligodendroglial" GBMO subtype showed additional aberrations exclusively in either the astrocytic (-(3)(p12-qter), $-4 \mathrm{q}$, $-6 \mathrm{q},-9 \mathrm{p},-13,-18)$ or the oligodendroglial $(-17 \mathrm{p})$ 
Table 3

Association between genetic subtypes and additional genetic alterations of GBMO

\begin{tabular}{|c|c|c|c|c|c|}
\hline & \multicolumn{2}{|c|}{ "Astrocytic" subtype } & \multirow{2}{*}{$\frac{\text { "Intermediate" subtype }}{\text { GBMO-H }(n=1)}$} & \multirow{2}{*}{$\frac{\text { "Oligodendroglial" subtype }}{\text { GBMO-H }(n=1)}$} & \multirow{2}{*}{$\frac{\text { "Other" subtype }}{\text { GBMO-H }(n=2)}$} \\
\hline & GBMO-R $(n=5)$ & GBMO-H $\left(n=4 / 3^{\mathrm{a}}\right)$ & & & \\
\hline $\operatorname{amp} E G F R$ & $3 / 5(60 \%)$ & $2 / 3(50 \%)$ & - & - & - \\
\hline$+19 q$ & $4 / 5(80 \%)$ & $1 / 4(25 \%)$ & - & - & - \\
\hline$+6 \mathrm{p}$ & $1 / 5(20 \%)$ & $2 / 3(66 \%)$ & - & - & - \\
\hline-11 & $3 / 5(60 \%)$ & - & - & - & - \\
\hline$+2 q$ & $1 / 5(20 \%)$ & $1 / 3(33 \%)$ & - & - & - \\
\hline+13 & $1 / 5(20 \%)$ & $2 / 3(66 \%)$ & - & - & - \\
\hline$+17 p$ & $2 / 5(40 \%)$ & $1 / 4(25 \%)$ & & & \\
\hline$+20 \mathrm{p}$ & $2 / 5(40 \%)$ & $1 / 3(33 \%)$ & - & - & - \\
\hline$+\mathrm{X}$ & $1 / 5(20 \%)$ & $1 / 3(33 \%)$ & - & - & - \\
\hline$+10 \mathrm{q} 23$ & - & - & - & - & $2 / 2(100 \%)$ \\
\hline$-16 \mathrm{p}$ & - & - & - & - & $2 / 2(100 \%)$ \\
\hline$+9 p$ & - & - & - & - & $2 / 2(100 \%)$ \\
\hline$-\mathrm{X}$ & - & - & - & $1 / 1(100 \%)$ & $2 / 2(100 \%)$ \\
\hline$-3 p$ & - & - & - & $1 / 1(100 \%)$ & $1 / 2(50 \%)$ \\
\hline amp7p21-15 & - & - & $1 / 1(100 \%)$ & - & - \\
\hline$-17 p$ & $1 / 5(20 \%)$ & - & - & $1 / 1(100 \%)$ & $2 / 2(100 \%)$ \\
\hline$-9 p$ & $3 / 5(60 \%)$ & - & - & $1 / 1(100 \%)$ & - \\
\hline
\end{tabular}

Notes: "Four GBMO-H of the "astrocytic" subtype were investigated using Interphase-FISH, but CGH results were only available for three tumors. Therefore the status of some aberrations is only known for three tumors. Abbreviations: GBM - "classic" glioblastoma; GBMO-H - GBM with oligodendroglial component and honeycomb appearance; GBMO-R - GBM with oligodendroglia-like, round tumor cells; - - aberration not found.

part. Aberrations only found in one histological part in the "astrocytic" subtype were in the astrocytic part: $+(4)(\mathrm{q} 25$-qter $),+(13)(\mathrm{q} 33$-qter $)[2 \times],+15$, $-(19 q)[2 \times], \operatorname{amp}(20 p),+21, \operatorname{amp}(21 q)$; and in the oligodendroglial part: $+2,+5 \mathrm{p},+9 \mathrm{p},+(12)$ (pterq21), $\operatorname{amp}(18)(q 11), \operatorname{amp}(20 q),-20,+21 q 22$. For the "other" subtype these included: +4 , $\operatorname{amp}(4)(q 12)$, $+(8)(q 21-23), \operatorname{amp}(11)(q 14-22),-12,-(16 p)[2 \times]$, $-(17 \mathrm{p})[2 \times],-22$ in the astrocytic part, and in the oligodendroglial part: $+(10 \mathrm{q})[2 \times],+(7 \mathrm{q})[2 \times],+(1 \mathrm{p})$, $\operatorname{amp}(2)(\mathrm{p} 23),-(9 \mathrm{q}),+17,+19,+21,-\mathrm{X}$. Notably, both tumors of the "other" showed the gain of chromosomes 7 and 10 only in their oligodendroglial part, while $-16 p$ and $-17 p$ were found only in the astrocytic parts. The "intermediate" tumor revealed -(13)(q14-21), -(15)(q15) exclusively in the oligodendroglial part and $+18 \mathrm{q}$ only in the astrocytic part.

We also found differences in ploidy among the two histological parts in some tumors (Table 2). The GBMO of the "oligodendroglial" subtype was diploid in the oligodendroglial and triploid in the astrocytic part. One "astrocytic" GBMO showed diploidy in most tumor cells of the astrocytic parts and triploidy in the tumor cells of the oligodendroglial parts. The remain- ing tumors demonstrated the same ploidy in both tumor parts.

Based on the Interphase-FISH results it was also possible to determine the frequencies of the heterogenetic cell clones in all tumors. To evaluate this information we designed a computer program that enabled us to also visualize the frequencies of the different clones in a 3-dimensional diagram (see Section 2). The coordinates of the diagram demonstrate the amounts of signals counted in one cell ( $x$-axes for the red-, $y$-axes for the blue and $z$-axis for the green signals) and the frequency of the cell clones are represented by the size of a sphere at the coordinates. An example is given in Fig. 3. Using this strategy we were able to see that the two different parts of some GBMO also differed with respect to the percentages of the several cell clones (Table 4). For example, the "oligodendroglial" GBMO showed the loss of $1 p$ and $19 q$ in $68 \%$ and $72 \%$ of cells in the oligodendroglial part respectively, but only in $44 \%$ and $38 \%$ of the cells in the astrocytic part respectively (Fig. 3, Table 4). Furthermore, whereas most tumor cells in the oligodendroglial part demonstrated both loss of $1 p$ and $19 q$, only a proportion of the cells 
Table 4

Frequencies of genetic alterations in the different histological parts of GBMOs investigated by Interphase-FISH

\begin{tabular}{|c|c|c|c|c|c|}
\hline ID & Histology & Genetic subtype & Aberration & $\begin{array}{l}\text { Amount of cells with the } \\
\text { aberration in the astrocytic } \\
\text { component }\end{array}$ & $\begin{array}{l}\text { Amount of cells with the } \\
\text { aberration in the } \\
\text { oligodendroglial component }\end{array}$ \\
\hline \multirow[t]{6}{*}{2} & GBMO-H & "astrocytic" & $+7 \mathrm{q}$ & $71 \%$ & $51 \%$ \\
\hline & & & $-\operatorname{cen} 18$ & $56 \%$ & $33 \%$ \\
\hline & & & $-10 \mathrm{q}$ & $51 \%$ & $42 \%$ \\
\hline & & & $-19 q$ & $51 \%$ & $(19 \%)$ \\
\hline & & & $+21 \mathrm{q} 11$ & $42 \%$ & $(10 \%)$ \\
\hline & & & $+17 \mathrm{p}$ & $(12 \%)$ & $34 \%$ \\
\hline \multirow[t]{4}{*}{5} & GBMO-R & "astrocytic" & +7 & $68 \%$ & $40 \%$ \\
\hline & & & -10 & $62 \%$ & $48 \%$ \\
\hline & & & $+19 \mathrm{q} 13.3$ & $37 \%$ & $(10 \%)$ \\
\hline & & & $-17 q 13$ & $(10 \%)$ & $(25 \%)$ \\
\hline \multirow[t]{2}{*}{8} & GBMO-R & "astrocytic" & $+7 \mathrm{q}$ & $50 \%$ & $61 \%$ \\
\hline & & & $+19 \mathrm{q} 13.3$ & $(4 \%)$ & $34 \%$ \\
\hline \multirow[t]{5}{*}{9} & GBMO-R & "astrocytic" & $+7 q$ & $69 \%$ & $90 \%$ \\
\hline & & & +1 & $54 \%$ & $88 \%$ \\
\hline & & & $+19 q$ & $53 \%$ & $76 \%$ \\
\hline & & & $+\operatorname{cen} 18$ & $43 \%$ & $(14 \%)$ \\
\hline & & & $-10 \mathrm{q}$ & $36 \%$ & $56 \%$ \\
\hline 12 & GBMO-R & "astrocytic" & $-17 p$ & $\mathbf{8 3 \%}$ & $64 \%$ \\
\hline \multirow[t]{3}{*}{6} & GBMO-H & "oligodendroglial" & $-\operatorname{cen} 18$ & $44 \%$ & $(5 \%)$ \\
\hline & & & $-1 p$ & $44 \%$ & $68 \%$ \\
\hline & & & $-19 q$ & $38 \%$ & $72 \%$ \\
\hline \multirow[t]{7}{*}{3} & GBMO-H & "other" & $+1 \mathrm{p} 32$ & $78 \%$ & $36 \%$ \\
\hline & & & $+1 \mathrm{q} 32$ & $49 \%$ & $68 \%$ \\
\hline & & & $-17 \mathrm{p} 13$ & $42 \%$ & $(28 \%)$ \\
\hline & & & $-19 \mathrm{q} 13.3$ & $37 \%$ & $(17 \%)$ \\
\hline & & & $-10 \mathrm{q} 23$ & $(27 \%)$ & $(10 \%)$ \\
\hline & & & $+10 \mathrm{q} 23$ & $(5 \%)$ & $47 \%$ \\
\hline & & & $+7 q 31.2$ & $(5 \%)$ & $47 \%$ \\
\hline \multirow[t]{7}{*}{11} & GBMO-H & "other" & $-19 q$ & $51 \%$ & $74 \%$ \\
\hline & & & $-17 p$ & $38 \%$ & $(28 \%)$ \\
\hline & & & $+\operatorname{cen} 18$ & $37 \%$ & $(10 \%)$ \\
\hline & & & +21 & $(29 \%)$ & $44 \%$ \\
\hline & & & $+1 \mathrm{p}$ & $(15 \%)$ & $44 \%$ \\
\hline & & & $+10 \mathrm{q} 23.3$ & $(10 \%)$ & $48 \%$ \\
\hline & & & $+7 q 31.2$ & $(5 \%)$ & $40 \%$ \\
\hline
\end{tabular}

Notes: Bold letters indicate in which histological part of the tumor the frequency of cells with the aberration is higher. Aberrations found in less than $20 \%$ of tumor cells are shown in brackets, because the cut off level was set to $30 \%$. Abbreviations: GBMO-H - glioblastoma with oligodendroglial component and honeycomb appearance; GBMO-R - glioblastoma with oligodendroglia-like, round tumor cells.

in the astrocytic part showed the loss of $1 \mathrm{p}$ but not the loss of $19 \mathrm{q}$.

We could not identify any special genetic changes typical for the oligodendroglial or the astrocytic parts that would have allowed us to distinguish between the two different histological parts.

\subsection{Correlation between genetic characteristics as well as clinical and pathological findings with respect to $O S$}

Histology: The OS of glioblastoma patients was different for the histological subtypes. Patients with 

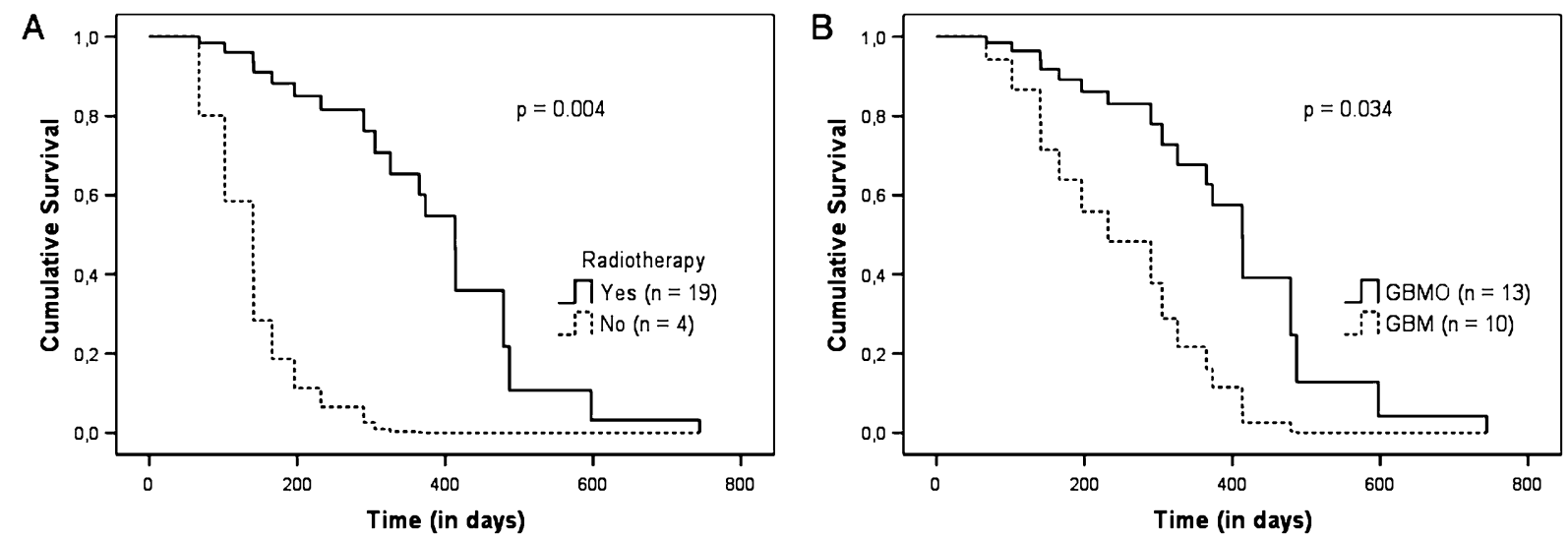

Fig. 5. Overall survival curves of glioblastoma patients (A) according to radiotherapy and (B) with or without oligodendroglial component. Abbreviations: GBMO - glioblastoma with oligodendroglial component; GBM - "classic" glioblastoma.

Table 5

Univariate and multivariate analyses of clinicopathologic and histologic predictors of survival in GBM (13 GBMO and 10 GBM)

\begin{tabular}{|c|c|c|c|c|c|c|}
\hline \multirow[t]{2}{*}{ Variable } & \multicolumn{3}{|c|}{ Univariate analysis } & \multicolumn{3}{|c|}{ Multivariate analysis } \\
\hline & RR & $95 \% \mathrm{CI}$ & $p$ & RR & $95 \% \mathrm{CI}$ & $p$ \\
\hline \multicolumn{7}{|l|}{ Age } \\
\hline \multicolumn{6}{|l|}{$>60$ years } & NS \\
\hline \multicolumn{7}{|l|}{ Gender } \\
\hline $\begin{array}{l}\text { male } \\
\text { female }\end{array}$ & 1.254 & $0.442-3.480$ & 0.663 & - & - & NS \\
\hline \multicolumn{7}{|l|}{ Radiation } \\
\hline $\begin{array}{l}\text { yes } \\
\text { no }\end{array}$ & 0.157 & $0.034-0.721$ & 0.007 & 0.074 & $0.013-0.434$ & 0.004 \\
\hline \multicolumn{7}{|l|}{ Chemotherapy } \\
\hline $\begin{array}{l}\text { yes } \\
\text { no }\end{array}$ & 0.579 & $0.215-1.560$ & 0.275 & - & - & NS \\
\hline \multicolumn{7}{|l|}{ Histology } \\
\hline $\begin{array}{l}\text { GBMO-H/R } \\
\text { GBM }\end{array}$ & 0.429 & $0.147-1.256$ & 0.112 & 0.256 & $0.074-0.887$ & $\mathbf{0 . 0 3 2}$ \\
\hline
\end{tabular}

Notes: Significant values are in bold type. $p$-values are two-sided. Abbreviations: RR - relative risk; CI - confidence interval; NS - not significant; GBM - "classic" glioblastoma; GBMO-H/R - glioblastoma with oligodendroglial component and honeycomb appearance/and oligodendroglialike, round tumor cells.

GBMO demonstrated longer OS (median $=404$ days) than patients with "classic" GBM (median $=282$ days) $(p=0.1)$ (Fig. 5, Table 5). However, there was no difference in survival between patients with either GBMO-H or GBMO-R ( $p=0.9)$.

Genetic subtypes: The two patients with tumors of the "other" subtype demonstrated the longest OS (median $=451$ days) compared to the "astrocytic" subtype (median = 357 days) and the "oligodendroglial" subtype (median $=365$ days) and the patient with the "intermediate" tumor had a poor prognosis as compared to the other three subtypes (102 days) $(p=0.02)$ (Table 5).

Clinics: We also investigated OS in relation to age ( $<60$ years vs. $>60$ years), gender, postoperative radiation and chemotherapy in univariate analyses. Patients aged less than 60 years exhibited a significantly longer OS $(p=0.05)$ as compared to older patients (Table 5). Patients who received radiation after surgery had significantly longer OS than patients with surgery alone ( $p=0.007$ ) (Table 5). No statistically significant difference was observed between male or female patients 
or between patients with and without chemotherapy.

Other genetic changes: Loss of the entire chromosome 19 was associated with a significantly poor prognosis in patients with GBMO $(p=0.005)$, while patients with a loss restricted to the long arm of chromosome 19 showed again a longer OS, although this was not statistically significant. Other genetic changes in GBMO associated with shorter OS were $+6 \mathrm{q}(p=$ $0.005),+13(p=0.01)$ and $-14(p=0.0003)$. Comparing the GBMO patients with OS $<1$ year and $>1$ year, the deletion of the long arm of chromosome 19 was exclusively found in the group with longer survival ( $p=0.05$ ) while loss of the entire chromosome 19 was only present in patients with survival of less than one year. All amplifications except of the EGFRlocus were exclusively found in patients who lived less than one year. There was no difference in the frequencies of $-9 \mathrm{p},+7,-10$ or amp7p12 (EGFR) between the two groups.

Multivariate analyses: Cox analyses including age, gender, radiation, chemotherapy and histology revealed the presence of an oligodendroglial component as an independent prognostic marker. GBMO patients showed a better prognosis than patients with "classic" GBM ( $p=0.03$ ). Radiation was found to show the highest influence on the prognosis $(p=0.004)$, improving survival significantly. In contrast, age as well as the genetic subtypes of GBMOs could not be used as independent prognostic markers in glioblastoma patients.

\section{Discussion}

The aim of this study was to characterize GBMOs in order to separately determine the genetic makeup of the astrocytic and the oligodendroglial parts and to attempt a subclassification of these tumors. To the best of our knowledge, this is the first study, which achieved this aim using a genome wide approach (CGH) in combination with a cell by cell analysis with InterphaseFISH.

The presence of areas with oligodendroglia-like differentiation in GBM has long been recognized by neuropathologists $[7,9,41]$, but the classification of these tumors remained unclear $[13,15,28]$. Although the new WHO classification of tumors of the central nervous system (2007) now includes glioblastomas with oligodendroglial component (GBMO) as a variant of GBM, definitive diagnostic criteria still do not exist [30,35].
Therefore, we reevaluated GBM cases histologically for the presence of a component resembling oligodendroglia-like features and reclassified them according to this component. GBM with areas consisting of cells with typical perinuclear halos and round nuclei assembling the typical honeycomb appearance were subclassified as GBMO-H. Tumors showing an additional component of GFAP-negative cells with uniform, round nuclei but no honeycomb appearance were defined as GBMO-R.

Using CGH and Interphase-FISH we identified four discrete genetic subtypes in GBMO: the first subtype with the combined gain of chromosome 7 and loss of chromosome 10 was called "astrocytic" subtype; the "oligodendroglial" subtype is characterized by $1 \mathrm{p}$ and $19 q$ codeletions; the "intermediate" subtype shows a combination of the former subtypes, i.e. gain of chromosome 7 and telomeric 1p deletion; the fourth subtype, lacking any of the previous aberrations typical for gliomas, was referred to as "other" subtype. Thus, the GBMOs were genetically heterogeneous, while all "classic" GBM we investigated corresponded genetically to the "astrocytic" subtype and all oligodendroglioma to the "oligodendroglial" subtype. Similar genetic subtypes as we define here in GBMO were also described in mixed gliomas [21]. The histological differentiation between GBMO-Hs and GBMO-Rs is also supported by our data since the group with typical honeycomb appearance (GBMO-H) comprised tumors of the "oligodendroglial", "intermediate" and "other" subtypes, while all GBMO-Rs belonged to the "astrocytic" subtype like "classic" GBMs. Further studies on mixed gliomas and oligodendrogliomas also showed that a stricter morphological classification increased the proportion of tumors with $1 \mathrm{p} / 19 \mathrm{q}$ codeletions [4, 21].

The most frequent aberrations found in 9 of 13 GBMOs were the gain of chromosome $7(12 / 13)$ and the loss of chromosome $10(9 / 13)$. He et al., in line with our results, showed that aberrations preferentially found in GBM (-10, EGFR amp, -9p) were also common in GBMOs [15], while Kraus et al. did not find a loss of chromosome 10 in 13 GBMOs [28].

The most common amplification spanned the $7 \mathrm{p} 12$ region containing the EGFR gene $(5 / 12)$ and was found only in "astrocytic" GBMOs with loss of chromosome 10. Previous studies on GBM showed that EGFR amplifications occurred only in tumors characterized by the loss of genetic material on chromosome 10 [37,55], suggesting an association between these two genetic events. 
One GBMO had a $1 \mathrm{p} / 19 \mathrm{q}$ codeletion and was referred to as "oligodendroglial" GBMO, whereas one other GBMO - subtype "intermediate" - demonstrated an isolated deletion of the terminal region of the short arm of chromosome 1 in combination with a gain of chromosome 7 . The separation between these two subtypes was done because the $1 \mathrm{p} / 19 \mathrm{q}$ codeletion typically found in oligodendrogliomas results from an unbalanced translocation $\mathrm{t}(1 ; 19)[14,20]$, but the isolated loss of $1 \mathrm{p} 36$ represents a characteristic finding in astrocytomas $[18,19]$. We hypothesize that the "intermediate" subtype is a different route in the progression of astrocytomas with a gain of chromosome 7 , which is an early change [48]. Here, the loss of a predicted tumor suppressor gene on 1p36 may lead to the development of grade IV GBMOs, in contrast to the "astrocytic" subtype with the subsequent deletion of one or more tumor suppressor genes on the long arm of chromosome 10.

The two GBMOs classified as "others" showed a gain of chromosome 9p. Recently, Korshunov et al. also reported a gain of chromosome $9 \mathrm{p}$ in $22 \%$ in GBMs of patients younger than 50 years of age and found it to be an independent prognostic factor for longer survival [25]. Our data support this observation, since the two patients with the GBMO subtype "other" experienced the longest survival. Furthermore, a gain on 10q23 was found in the "astrocytic" component of both "other" GBMOs, which is an unusual finding in gliomas and was not found in any of the other tumors investigated.

Loss of chromosomal material on $17 \mathrm{p} 13$ including the TP53 gene locus was found in four of 13 GBMO and two of $10 \mathrm{GBM}$. Interestingly, 17p13 deletions occurred in GBMO of the "astrocytic", "oligodendroglial" and "other" subtypes and in combination with both the $1 \mathrm{p} / 19 \mathrm{q}$ deletion as well as the EGFR amplification. It has often been suggested, that deletions or mutations of TP53 are common in secondary GBM, while EGFR amplifications are judged as a typical change in primary GBM $[39,47]$. A recent genome wide study on GBM now proved that TP53 mutations are also a common event in primary GBM [36]. Altogether, these data render the TP53 changes an independent step in glioma tumorigenesis. Walker et al. also found the 17p13 loss (i) in an oligodendroglioma with the $1 \mathrm{p} / 19 \mathrm{q}$ codeletion and (ii) in all histological variants he investigated (oligodendrogliomas, astrocytomas and mixed gliomas) [56].

Previous studies concerning the different impact of GBMO vs. GBM on prognosis revealed inconsistent results. While some studies found the presence of an oligodendroglial component in GBM to be associated with longer OS $[16,17,46]$, a recent study could not find any significant difference in survival between patients with GBMO and "classic" GBM [42]. In our study, patients with GBMO (GBMO-H and GBMOR) had a longer median survival than patients with "classic" GBM and the presence of an oligodendroglial component of GBM was a significant independent predictor of longer OS in multivariate analyses with adjustments for age, gender and treatment $(p=0.034)$.

A major task of this study was to verify if the different histological parts of GBMOs are based on separate genetic profiles. Previous studies of mixed gliomas have found identical genetic changes of certain genes or regions in the two different components, which supports the hypothesis of a monoclonal origin [27,42,43, 56]. Others found different genetic changes in some heterogeneous tumors and therefore discussed a biclonal origin in a proportion of mixed gliomas [10, 43]. However, these studies looked at defined genes or regions and therefore evaluated only a small proportion of the genome. Our study is the first one using a genome wide approach (CGH) to analyze the two different histological parts within the GBMOs. We found that the two different parts of the GBMOs were concordant for most aberrations, thus supporting the hypothesis of a monoclonal origin. Interestingly, the signature genetic changes that separate the four genetic subtypes (e.g., $+7 /-10,-1 \mathrm{p} /-19 \mathrm{q},-1 \mathrm{p} 36 /+7,+9 \mathrm{p})$ were always present in both tumor parts. One may speculate that the origin of the GBMOs occurred in a brain (tumor) (stem) cell, which grew into a cell clone characterized by the subtype specific aberrations. Since all GBMO showed additional aberrations in the different tumor components, the hypothesis of a subsequent process of differentiation and progression during clonal expansion of the original clone into two different parts with distinct morphological appearance seams intriguing. For example, the GBMO with $-1 p /-19 q$ showed $-1 p /-19 q$ in both parts, suggesting that this was the underlying aberration leading to this tumor with an oligodendroglial genetic makeup. The astrocytic part of this GBMO also showed the $-1 p /-19 q$ and additional aberrations $(-3 p 12-$ qter, $-4 \mathrm{q},-6 \mathrm{q},-9 \mathrm{p},-13,-18)$ including polyploidy, which are (except -3 p12-qter) known to be associated with progression and/or poor prognosis in gliomas $[2,11,34,45,52,57,59]$. Because the histological evaluation revealed a GFAP positive area with distinct astrocytic features and necrosis the tumor was classified as 
GBMO. The patient only survived for one year, which argues for a grade IV tumor.

The investigated GBMOs demonstrated altogether common aberrations in a high number of cells in spite of the wide range of additional aberrations and even the differences in ploidy within the same tumor area on a single cell level. Thus, we provide strong evidence for a monoclonal origin of all GBMOs studied, even so they comprised phenotypically different astrocytic and oligodendroglial parts. Furthermore, a genetic subclassification of GBMO may become possible, since we identified four subtypes with different genetic profiles. Prospective and detailed molecular cytogenetic studies of gliomas altogether and of mixed gliomas in particular should be performed large scale in order to contribute to the evaluation of the different genetic markers as possible biomarkers for a more profound subclassification, for the prognostication of treatment response as well as for the development of targeted therapies.

\section{Acknowledgement}

This work was supported by a research grant from the Interdisziplinäres Zentrum für Klinische Forschung (IZKF) at the Medizinische Fakultät der FriedrichSchiller Universität Jena, Germany.

\section{References}

[1] N. Aldosari, R.N. Wiltshire, A. Dutra, E. Schrock, R.E. McLendon, H.S. Friedman, D.D. Bigner and S.H. Bigner, Comprehensive molecular cytogenetic investigation of chromosomal abnormalities in human medulloblastoma cell lines and xenograft, Neuro Oncol. 4 (2002), 75-85.

[2] S.H. Bigner, M.R. Matthews, B.K. Rasheed, R.N. Wiltshire, H.S. Friedman, A.H. Friedman, T.T. Stenzel, D.M. Dawes, R.E. McLendon and D.D. Bigner, Molecular genetic aspects of oligodendrogliomas including analysis by comparative genomic hybridization, Am. J. Pathol. 155 (1999), 375-386.

[3] S.H. Bigner and E. Schrock, Molecular cytogenetics of brain tumors, J. Neuropathol. Exp. Neurol. 56 (1997), 1173-1181.

[4] J.E. Bromberg and M.J. van den Bent, Oligodendrogliomas: molecular biology and treatment, Oncologist 14 (2009), $155-163$.

[5] G. Cairncross, B. Berkey, E. Shaw, R. Jenkins, B. Scheithauer, D. Brachman, J. Buckner, K. Fink, L. Souhami, N. Laperierre, M. Mehta and W. Curran, Phase III trial of chemotherapy plus radiotherapy compared with radiotherapy alone for pure and mixed anaplastic oligodendroglioma: Intergroup Radiation Therapy Oncology Group Trial 9402, J. Clin. Oncol. 24 (2006), 2707-2714.
[6] J.G. Cairncross, K. Ueki, M.C. Zlatescu, D.K. Lisle, D.M. Finkelstein, R.R. Hammond, J.S. Silver, P.C. Stark, D.R. Macdonald, Y. Ino, D.A. Ramsay and D.N. Louis, Specific genetic predictors of chemotherapeutic response and survival in patients with anaplastic oligodendrogliomas, J. Natl. Cancer Inst. 90 (1998), 1473-1479.

[7] S.W. Coons, P.C. Johnson, B.W. Scheithauer, A.J. Yates and D.K. Pearl, Improving diagnostic accuracy and interobserver concordance in the classification and grading of primary gliomas, Cancer 79 (1997), 1381-1393.

[8] C. Daumas-Duport, B. Scheithauer, J. O'Fallon and P. Kelly, Grading of astrocytomas. A simple and reproducible method, Cancer 62 (1988), 2152-2165.

[9] C. Decaestecker, I. Camby, L. Gordower, O. Dewitte, P. Cras, J.J. Martin, J.L. Pasteels, P.V. Ham, J. Brotchi, R. Kiss and I. Salmon, Characterization of astroglial versus oligodendroglial phenotypes in glioblastomas by means of quantitative morphonuclear variables generated by computer-assisted microscopy, J. Neuropathol. Exp. Neurol. 57 (1998), 791-802.

[10] Z.-Q. Dong, J.C.-S. Pang, C.Y.-K. Tong, L.-F. Zhou and H.-K. Ng, Clonality of oligoastrocytomas, Hum. Pathol. 33 (2002), 528-535.

[11] K.B. Fallon, C.A. Palmer, K.A. Roth, L.B. Nabors, W. Wang, M. Carpenter, R. Banerjee, P. Forsyth, K. Rich and A. Perry, Prognostic value of 1p, 19q, 9p, 10q, and EGFR-FISH analyses in recurrent oligodendrogliomas, J. Neuropathol. Exp. Neurol. 63 (2004), 314-322.

[12] J. Felsberg, A. Erkwoh, M.C. Sabel, L. Kirsch, R. Fimmers, B. Blaschke, U. Schlegel, J. Schramm, O.D. Wiestler and G. Reifenberger, Oligodendroglial tumors: refinement of candidate regions on chromosome arm $1 \mathrm{p}$ and correlation of 1p/19q status with survival, Brain Pathol. 14 (2004), 121-130.

[13] C.E. Fuller, R.E. Schmidt, K.A. Roth, P.C. Burger, B.W. Scheithauer, R. Banerjee, K. Trinkaus, R. Lytle and A. Perry, Clinical utility of fluorescence in situ hybridization (FISH) in morphologically ambiguous gliomas with hybrid oligodendroglial/astrocytic features, J. Neuropathol. Exp. Neurol. 62 (2003), 1118-1128.

[14] C.A. Griffin, P. Burger, L. Morsberger, R. Yonescu, S. Swierczynski, J.D. Weingart and K.M. Murphy, Identification of $\operatorname{der}(1 ; 19)(\mathrm{q} 10 ; \mathrm{p} 10)$ in five oligodendrogliomas suggests mechanism of concurrent $1 \mathrm{p}$ and $19 \mathrm{q}$ loss, J. Neuropathol. Exp. Neurol. 65 (2006), 988-994.

[15] J. He, K. Mokhtari, M. Sanson, Y. Marie, M. Kujas, S. Huguet, P. Leuraud, L. Capelle, J.Y. Delattre, J. Poirier and K. HoangXuan, Glioblastomas with an oligodendroglial component: a pathological and molecular study, J. Neuropathol. Exp. Neurol. 60 (2001), 863-871.

[16] D.A. Hilton, M. Penney, L. Pobereskin, H. Sanders and S. Love, Histological indicators of prognosis in glioblastomas: retinoblastoma protein expression and oligodendroglial differentiation indicate improved survival, Histopathology $\mathbf{4 4}$ (2004), 555-560.

[17] T. Homma, T. Fukushima, S. Vaccarella, Y. Yonekawa, P.L.D. Patre, S. Franceschi and H. Ohgaki, Correlation among pathology, genotype, and patient outcomes in glioblastoma, J. Neuropathol. Exp. Neurol. 65 (2006), 846-854.

[18] K. Ichimura, A.P. Vogazianou, L. Liu, D.M. Pearson, L.M. Backlund, K. Plant, K. Baird, C.F. Langford, S.G. Gregory and V.P. Collins, 1p36 is a preferential target of chromosome 1 deletions in astrocytic tumours and homozygously 
deleted in a subset of glioblastomas, Oncogene 27 (2008), 2097-2108.

[19] A. Idbaih, Y. Marie, G. Pierron, C. Brennetot, K. Hoang-Xuan, M. Kujas, K. Mokhtari, M. Sanson, J. Lejeune, A. Aurias, O. Delattre and J.Y. Delattre, Two types of chromosome 1p losses with opposite significance in gliomas, Ann. Neurol. 58 (2005), 483-487.

[20] R.B. Jenkins, H. Blair, K.V. Ballman, C. Giannini, R.M. Arusell, M. Law, H. Flynn, S. Passe, S. Felten, P.D. Brown, E.G. Shaw and J.C. Buckner, A $t(1 ; 19)(\mathrm{q} 10 ; \mathrm{p} 10)$ mediates the combined deletions of $1 p$ and $19 q$ and predicts a better prognosis of patients with oligodendroglioma, Cancer Res. $\mathbf{6 6}$ (2006), 9852-9861.

[21] J.W. Jeuken, S.H. Sprenger, R.H. Boerman, A. von Deimling, H.L. Teepen, J.J. van Overbeeke and P. Wesseling, Subtyping of oligo-astrocytic tumours by comparative genomic hybridization, J. Pathol. 194 (2001), 81-87.

[22] P. Kleihues, P.C. Burger, K.D. Aldape, D.J. Brat, W. Biernat, D.D. Bigner, Y. Nakazato, K.H. Plate, F. Giangaspero, A. von Deimling, H. Ohgaki and W.K. Cavenee, Glioblastoma, in: WHO Classification of Tumours of the Central Nervous System, D.N. Louis, H. Ohgaki, O.D. Wiestler and W.K. Cavenee, eds, International Agency for Research on Cancer (IARC) Press, Lyon, 2007, pp. 33-49.

[23] P. Kleihues and W.K. Cavenee, Pathology and Genetics of Tumours of the Nervous System, World Health Organization Classification of Tumours, International Agency for Research on Cancer (IARC) Press, Lyon, 2000.

[24] C.A. Klein, O. Schmidt-Kittler, J.A. Schardt, K. Pantel, M.R. Speicher and G. Riethmüller, Comparative genomic hybridization, loss of heterozygosity, and DNA sequence analysis of single cells, Proc. Natl. Acad. Sci. USA 96 (1999), 44944499.

[25] A. Korshunov, R. Sycheva and A. Golanov, The prognostic relevance of molecular alterations in glioblastomas for patients age $<50$ years, Cancer 104 (2005), 825-832.

[26] R. Koschny, T. Koschny, U.G. Froster, W. Krupp and M.A. Zuber, Comparative genomic hybridization in glioma: a metaanalysis of 509 cases, Cancer Genet. Cytogenet. 135 (2002), $147-159$.

[27] J.A. Kraus, J. Koopmann, P. Kaskel, D. Maintz, S. Brandner, J. Schramm, D.N. Louis, O.D. Wiestler and A. von Deimling, Shared allelic losses on chromosomes $1 \mathrm{p}$ and 19q suggest a common origin of oligodendroglioma and oligoastrocytoma, J. Neuropathol. Exp. Neurol. 54 (1995), 91-95.

[28] J.A. Kraus, K. Lamszus, N. Glesmann, M. Beck, M. Wolter, M. Sabel, D. Krex, T. Klockgether, G. Reifenberger and U. Schlegel, Molecular genetic alterations in glioblastomas with oligodendroglial component, Acta Neuropathol. (Berlin) 101 (2001), 311-320.

[29] C. Lengauer, I. Dunham, T. Featherstone and T. Cremer, Generation of alphoid DNA probes for fluorescence in situ hybridization (FISH) using the polymerase chain reaction, Methods Mol. Biol. 33 (1994), 51-61.

[30] D.N. Louis, H. Ohgaki, O.D. Wiestler, W.K. Cavenee, P.C. Burger, A. Jouvet, B.W. Scheithauer and P. Kleihues, The 2007 WHO classification of tumours of the central nervous system, Acta Neuropathol. 114 (2007), 97-109.

[31] C.R. Miller and A. Perry, Glioblastoma, Arch. Pathol. Lab. Med. 131 (2007), 397-406.
[32] A. Misra, M. Pellarin, J. Nigro, I. Smirnov, D. Moore, K.R. Lamborn, D. Pinkel, D.G. Albertson and B.G. Feuerstein, Array comparative genomic hybridization identifies genetic subgroups in grade 4 human astrocytoma, Clin. Cancer Res. 11 (2005), 2907-2918.

[33] T. Nagasaka, M. Gunji, N. Hosokai, K. Hayashi, H. Ikeda, M. Ito and S. Inao, FISH 1p/19q deletion/imbalance for molecular subclassification of glioblastoma, Brain Tumor Pathol. 24 (2007), 1-5.

[34] M. Nakamura, F. Yang, H. Fujisawa, Y. Yonekawa, P. Kleihues and H. Ohgaki, Loss of heterozygosity on chromosome 19 in secondary glioblastomas, J. Neuropathol. Exp. Neurol. 59 (2000), 539-543.

[35] Y. Nakazato, K.H. Plate, F. Giangaspero, A. von Deimling, H. Ohgaki and W.K. Cavenee, Glioblastoma, in: WHO Classification of Tumours of the Nervous System, D.N. Louis, H. Ohgaki, O.D. Wiestler and W.K. Cavenee, eds, IARC, Lyon, 2007, pp. 33-49.

[36] T.C.G.A.R. Network, Comprehensive genomic characterization defines human glioblastoma genes and core pathways, $\mathrm{Na}$ ture 455 (2008), 1061-1068.

[37] T. Nishizaki, S. Ozaki, K. Harada, H. Ito, H. Arai, T. Beppu and K. Sasaki, Investigation of genetic alterations associated with the grade of astrocytic tumor by comparative genomic hybridization, Genes Chromosomes Cancer 21 (1998), 340-346.

[38] H. Ohgaki and P. Kleihues, Population-based studies on incidence, survival rates, and genetic alterations in astrocytic and oligodendroglial gliomas, J. Neuropathol. Exp. Neurol. 64 (2005), 479-489.

[39] H. Ohgaki and P. Kleihues, Genetic pathways to primary and secondary glioblastoma, Am. J. Pathol. 170 (2007), 14451453.

[40] S. Patt, H. Gries, M. Giraldo, J. Cervos-Navarro, H. Martin, W. Jänisch and J. Brockmöller, p53 gene mutations in human astrocytic brain tumors including pilocytic astrocytomas, Hum. Pathol. 27 (1996), 586-589.

[41] W. Paulus and J. Peiffer, Intratumoral histologic heterogeneity of gliomas. A quantitative study, Cancer 64 (1989), 442-447.

[42] L.W. Pinto, M.B. Araujo, A.L. Vettore, L. Wernersbach, A.C. Leite, L.M. Chimelli and F.A. Soares, Glioblastomas: correlation between oligodendroglial components, genetic abnormalities, and prognosis, Virchows Arch. 452 (2008), 481490.

[43] M. Qu, T. Olofsson, S. Sigurdardottir, C. You, H. Kalimo, M. Nister, A. Smits and Z.P. Ren, Genetically distinct astrocytic and oligodendroglial components in oligoastrocytomas, Acta Neuropathol. 113 (2007), 129-136.

[44] K.S. Reddy, Assessment of $1 \mathrm{p} / 19 \mathrm{q}$ deletions by fluorescence in situ hybridization in gliomas, Cancer Genet. Cytogenet. 184 (2008), 77-86.

[45] G. Reifenberger and D.N. Louis, Oligodendroglioma: toward molecular definitions in diagnostic neuro-oncology, $\mathrm{J}$. Neuropathol. Exp. Neurol. 62 (2003), 111-126.

[46] M. Salvati, A.I. Formichella, A. D'Elia, C. Brogna, A. Frati, F. Giangaspero, R. Delfini and A. Santoro, Cerebral glioblastoma with oligodendrogliomal component: analysis of 36 cases, J. Neurooncol. 94 (2009), 129-134.

[47] M.C. Schmidt, S. Antweiler, N. Urban, W. Mueller, A. Kuklik, B. Meyer-Puttlitz, O.D. Wiestler, D.N. Louis, R. Fimmers and A. von Deimling, Impact of genotype and morphology on 
the prognosis of glioblastoma, J. Neuropathol. Exp. Neurol. 61 (2002), 321-328.

[48] E. Schrock, C. Blume, M.C. Meffert, S. du Manoir, W. Bersch, M. Kiessling, T. Lozanowa, G. Thiel, R. Witkowski, T. Ried and T. Cremer, Recurrent gain of chromosome arm 7q in lowgrade astrocytic tumors studied by comparative genomic hybridization, Genes Chromosomes Cancer 15 (1996), 199-205.

[49] E. Schrock, G. Thiel, T. Lozanova, S. du Manoir, M.C. Meffert, A. Jauch, M.R. Speicher, P. Nürnberg, S. Vogel and W. Jänisch, Comparative genomic hybridization of human malignant gliomas reveals multiple amplification sites and nonrandom chromosomal gains and losses, Am. J. Pathol. 144 (1994), 1203-1218.

[50] J.S. Smith, A. Perry, T.J. Borell, H.K. Lee, J. O'Fallon, S.M. Hosek, D. Kimmel, A. Yates, P.C. Burger, B.W. Scheithauer and R.B. Jenkins, Alterations of chromosome arms $1 p$ and $19 \mathrm{q}$ as predictors of survival in oligodendrogliomas, astrocytomas, and mixed oligoastrocytomas, J. Clin. Oncol. 18 (2000), 636-645.

[51] B. Tews, J. Felsberg, C. Hartmann, A. Kunitz, M. Hahn, G. Toedt, K. Neben, L. Hummerich, A. von Deimling, G. Reifenberger and P. Lichter, Identification of novel oligodendroglioma-associated candidate tumor suppressor genes in $1 \mathrm{p} 36$ and $19 \mathrm{q} 13$ using microarray-based expression profiling, Int. J. Cancer 119 (2006), 792-800.

[52] D. Trost, M. Ehrler, R. Fimmers, J. Felsberg, M.C. Sabel, L. Kirsch, J. Schramm, O.D. Wiestler, G. Reifenberger and R.G. Weber, Identification of genomic aberrations associated with shorter overall survival in patients with oligodendroglial tumors, Int. J. Cancer 120 (2007), 2368-2376.

[53] K. Ueki, R. Nishikawa, Y. Nakazato, T. Hirose, J. Hirato, N. Funada, T. Fujimaki, S. Hojo, O. Kubo, T. Ide, M. Usui, C. Ochiai, S. Ito, H. Takahashi, A. Mukasa, A. Asai and T. Kirino, Correlation of histology and molecular genetic analysis of 1p, 19q, 10q, TP53, EGFR, CDK4, and CDKN2A in 91 astrocytic and oligodendroglial tumors, Clin. Cancer Res. 8 (2002), 196-201.

[54] M.J. van den Bent, A.F. Carpentier, A.A. Brandes, M. Sanson,
M.J.B. Taphoorn, H.J.J.A. Bernsen, M. Frenay, C.C. Tijssen, W. Grisold, L. Sipos, H. Haaxma-Reiche, J.M. Kros, M.C.M. van Kouwenhoven, C.J. Vecht, A. Allgeier, D. Lacombe and T. Gorlia, Adjuvant procarbazine, lomustine, and vincristine improves progression-free survival but not overall survival in newly diagnosed anaplastic oligodendrogliomas and oligoastrocytomas: a randomized European Organisation for Research and Treatment of Cancer phase III trial, J. Clin. Oncol. 24 (2006), 2715-2722.

[55] A. von Deimling, D.N. Louis, K. von Ammon, I. Petersen, T. Hoell, R.Y. Chung, R.L. Martuza, D.A. Schoenfeld, M.G. Yaşargil and O.D. Wiestler, Association of epidermal growth factor receptor gene amplification with loss of chromosome 10 in human glioblastoma multiforme, J. Neurosurg. 77 (1992), 295-301.

[56] C. Walker, D.G. du Plessis, K.A. Joyce, Y. Machell, J. Thomson-Hehir, S.A.A. Haddad, J.C. Broome and P.C. Warnke, Phenotype versus genotype in gliomas displaying inter- or intratumoral histological heterogeneity, Clin. Cancer Res. 9 (2003), 4841-4851.

[57] R.G. Weber, M. Sabel, J. Reifenberger, C. Sommer, J. Oberstrass, G. Reifenberger, M. Kiessling and T. Cremer, Characterization of genomic alterations associated with glioma progression by comparative genomic hybridization, Oncogene $\mathbf{1 3}$ (1996), 983-994.

[58] P.H. Wessels, A. Twijnstra, A.G.H. Kessels, B. Krijne-Kubat, P.H. Theunissen, M.I.J. Ummelen, F.C.S. Ramaekers and A.H. Hopman, Gain of chromosome 7, as detected by in situ hybridization, strongly correlates with shorter survival in astrocytoma grade 2, Genes Chromosomes Cancer 33 (2002), 279284.

[59] E.C. Wooten, D. Fults, R. Duggirala, K. Williams, A.P. Kyritsis, M.L. Bondy, V.A. Levin and P. O'Connell, A study of loss of heterozygosity at 70 loci in anaplastic astrocytoma and glioblastoma multiforme with implications for tumor evolution, Neuro Oncol. 1 (1999), 169-176. 


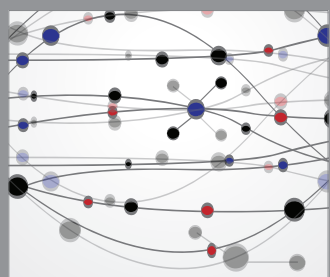

The Scientific World Journal
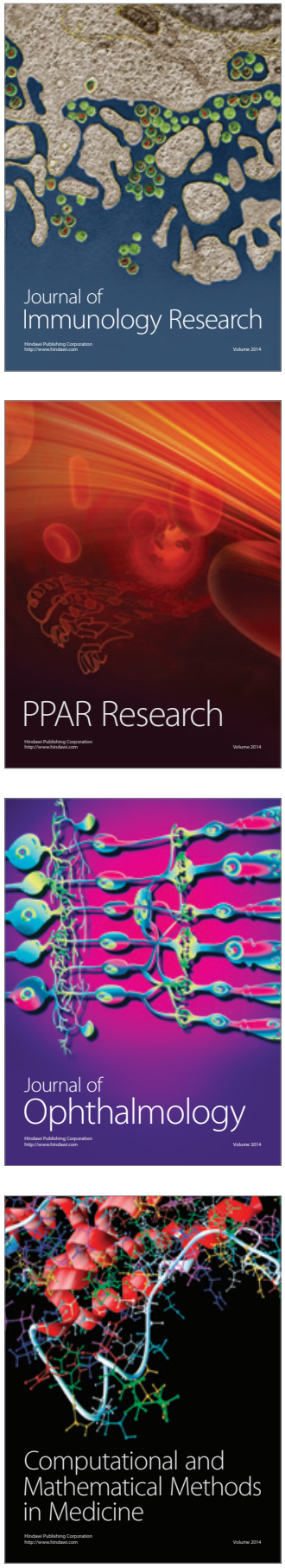

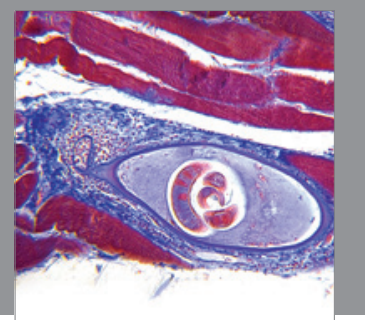

Gastroenterology

Research and Practice
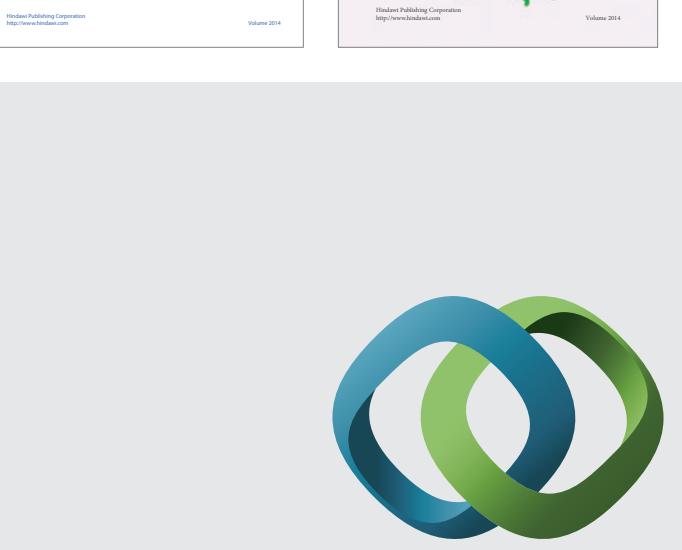

\section{Hindawi}

Submit your manuscripts at

http://www.hindawi.com
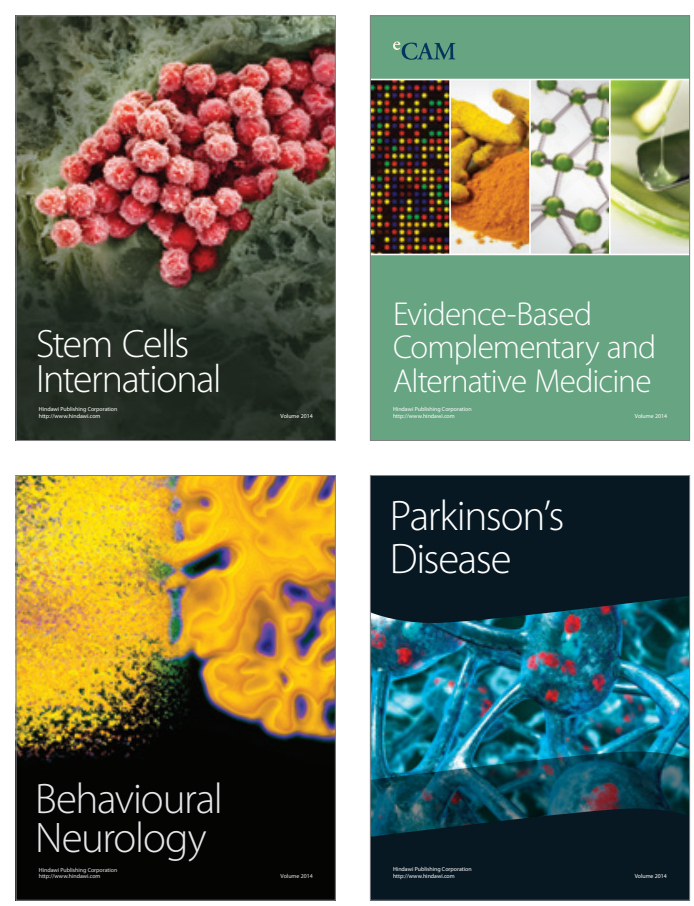

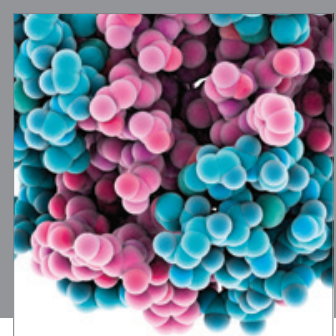

Journal of
Diabetes Research

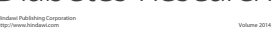

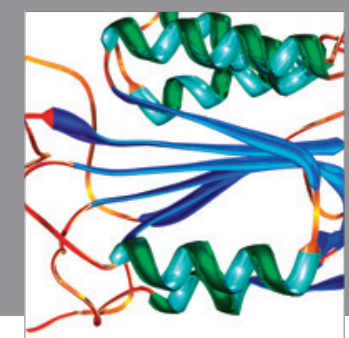

Disease Markers
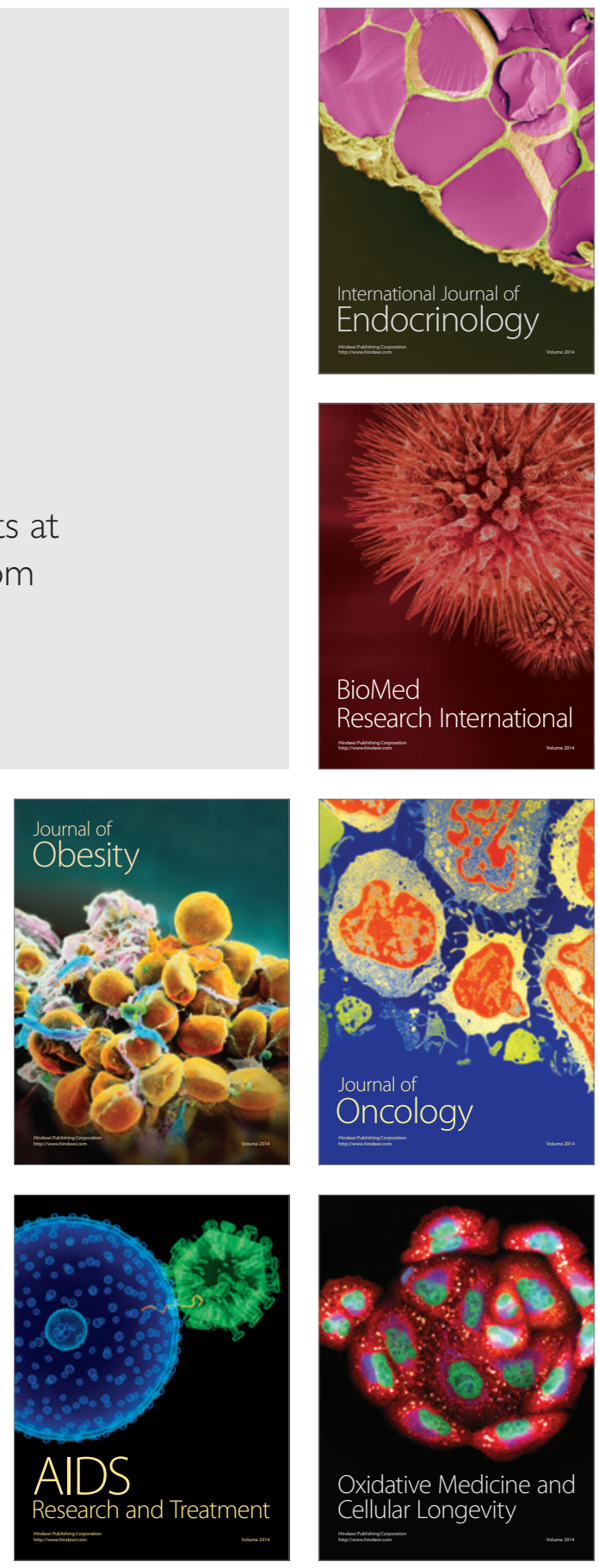